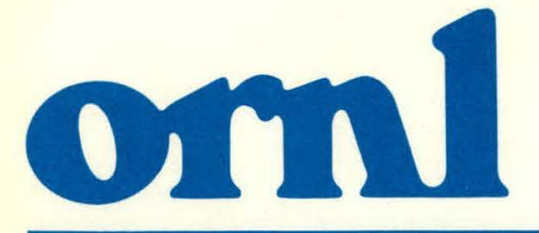

OAK

RIDGE NATIONAL LABORATORY

UNION CARBIDE
Screening Study on High Temperature Energy Transport Systems

\author{
R. L. Graves
}

MASTER
OPERATED BY

UNION CARBIDE CORPORATION FOR THE UNITED STATES DEPARTMENT OF ENERGY 


\section{DISCLAIMER}

This report was prepared as an account of work sponsored by an agency of the United States Government. Neither the United States Government nor any agency Thereof, nor any of their employees, makes any warranty, express or implied, or assumes any legal liability or responsibility for the accuracy, completeness, or usefulness of any information, apparatus, product, or process disclosed, or represents that its use would not infringe privately owned rights. Reference herein to any specific commercial product, process, or service by trade name, trademark, manufacturer, or otherwise does not necessarily constitute or imply its endorsement, recommendation, or favoring by the United States Government or any agency thereof. The views and opinions of authors expressed herein do not necessarily state or reflect those of the United States Government or any agency thereof. 


\section{DISCLAIMER}

Portions of this document may be illegible in electronic image products. Images are produced from the best available original document. 
Printed in the United States of America. Available from National Technical Information Sorvico

U.S. Department of Commerce

5285 Port Royal Road, Springfield, Virginia 22161

NTIS price codes-Printed Copy: A04; Microfiche A01

This report was prepared as an account of work sponsored by an agency of the United States Government. Neither the United States Government nor any agency thereof, nor any of their employees, makes any warranty, express or implied, or assumes any legal liability or responsibility for the accuracy, completeness, or usefulness of any information, apparatus, product, or process disclosed, or represents that its use would not infringe privately owned rights. Reference herein to any specific commercial product, process, or service by trade name, trademark, manufacturer, or otherwise, does not necessarily constitute or imply its endnrsement, rer.nmmendatinn or favnring hy the United States Government or any agency therenf The views and npinions nf authors expressed herein do not necessarily state or reflect those of the United States Government or any agency thereof. 


\section{Screening Study on High Temperature Energy Transport Systems}

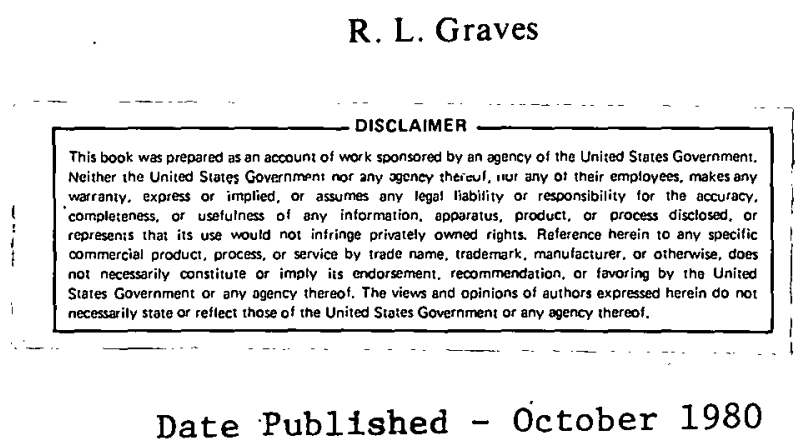

NOTICE This document contains information of a preliminary nature. It is subject to revision or correction and therefore does not represent a final report.

Prepared by the OAK RIDGE NATIONAL LABORATORY Oak Ridge, Tennessee 37830 operated by UNION CARBIDE CORPORATION for the DEPARTMENT OF ENERGY 
THIS PAGE

\section{WAS INTENTIONALLY \\ LEFT BLANK}




\section{CONTENTS}

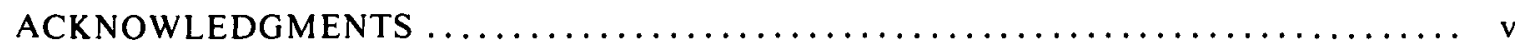

LIST OF ABBREVIATIONS $\ldots \ldots \ldots \ldots \ldots \ldots \ldots \ldots \ldots \ldots \ldots \ldots \ldots \ldots \ldots \ldots \ldots \ldots \ldots \ldots \ldots$

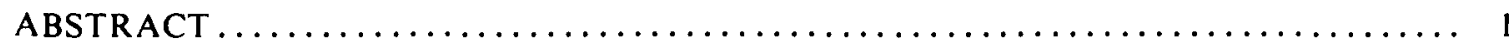

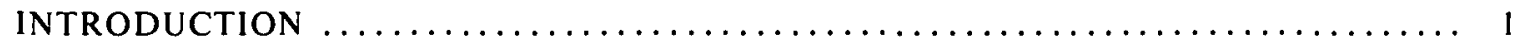

IDENTIFICATION OF CONCEPTS FOR MOVING

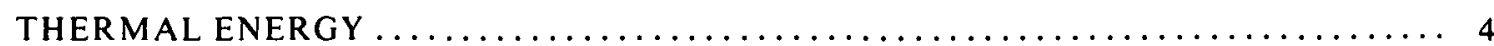

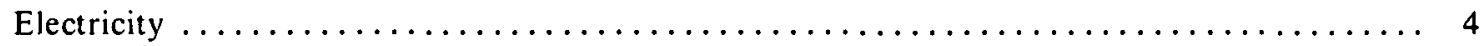

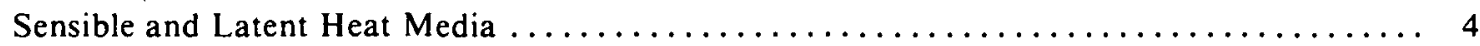

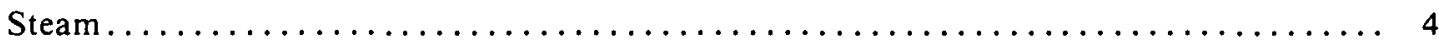

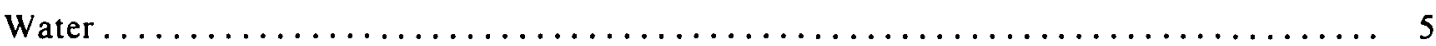

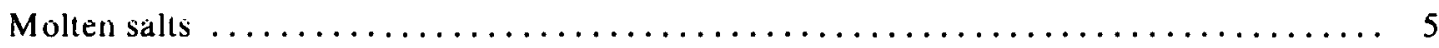

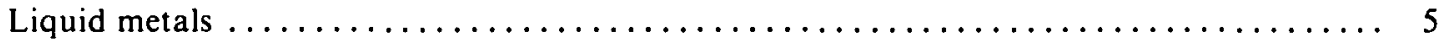

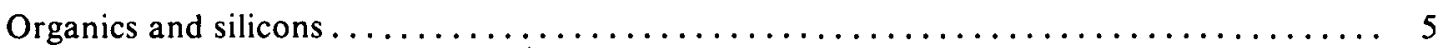

Chemical Reaction Heat Pipes.................................... 7

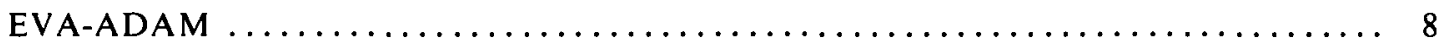

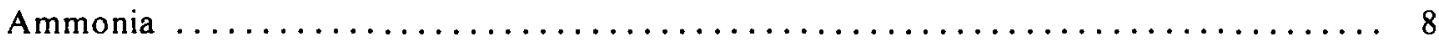

FUNDAMENTAL COMPARISON OF ENERGY

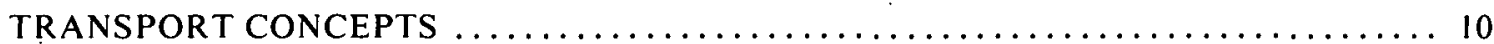

STATE OF THE ART AND ONGOING RESEARCH

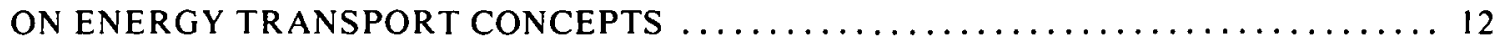

Industrial Electric Heat Pump ....................................... 12

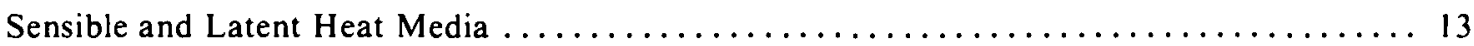

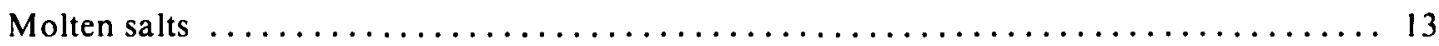

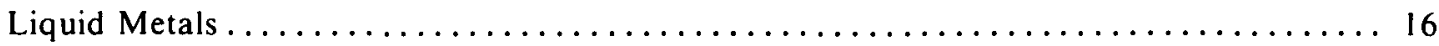

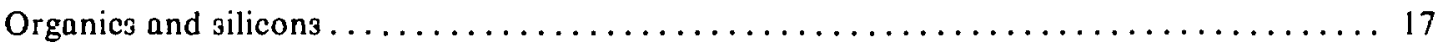

THERMOCHEMICAL ENERGY TRANSPORT SYSTEMS $\ldots \ldots \ldots \ldots \ldots \ldots \ldots \ldots \ldots$

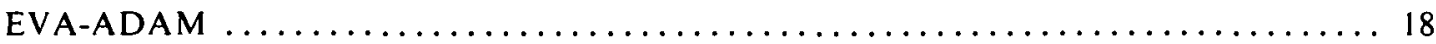

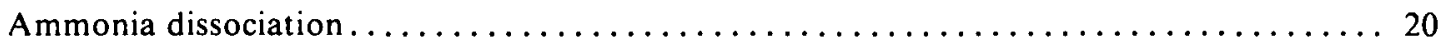

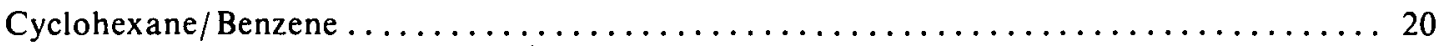

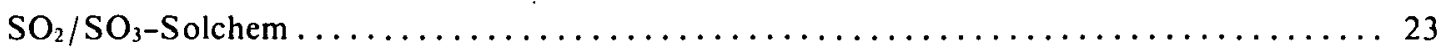

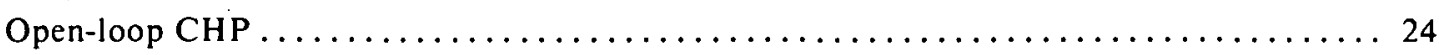

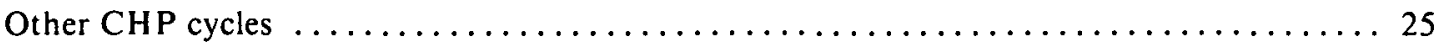

PRELIMINARY ECONOMIC ASSESSMENT OF

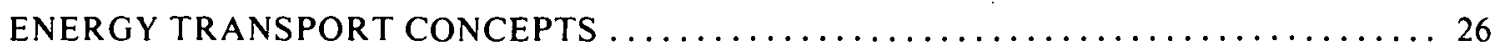

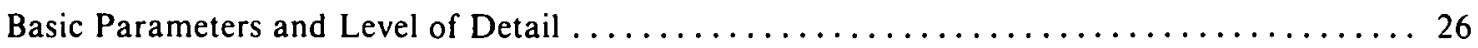

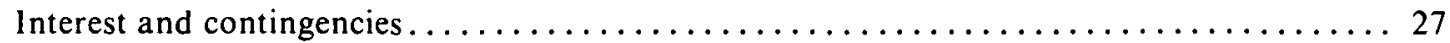

Comparison of annual costs ................................... 29 
Effect of heat exchanger and chemical reactor costs $\ldots \ldots \ldots \ldots \ldots \ldots \ldots \ldots \ldots \ldots \ldots, 30$

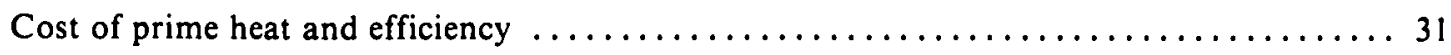

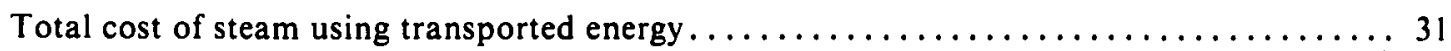

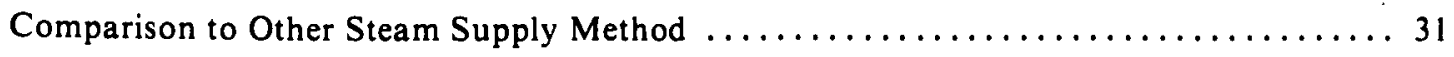

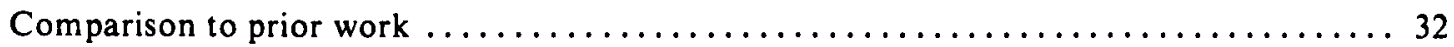

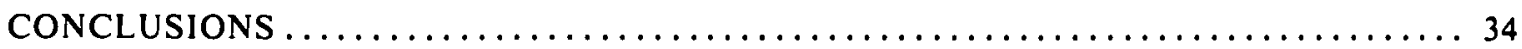

RECOMMENDATIONS FOR FUTURE WORK $\ldots \ldots \ldots \ldots \ldots \ldots \ldots \ldots \ldots \ldots \ldots \ldots \ldots \ldots \ldots \ldots$

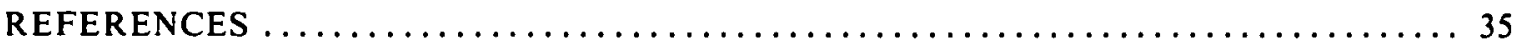

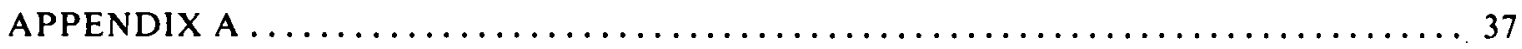

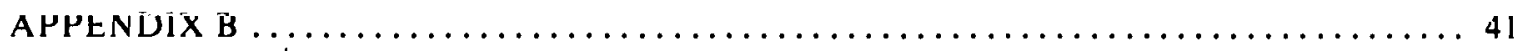




\section{ACKNOWLEDGMENTS}

The author acknowledges and is grateful for the contributions made by S. Cantor, D. E. Brashears, and T. Shapiro. 


\section{THIS PAGE}

\section{WAS INTENTIONALLY \\ LEFT BLANK}




\section{LIST OF ABBREVIATIONS}

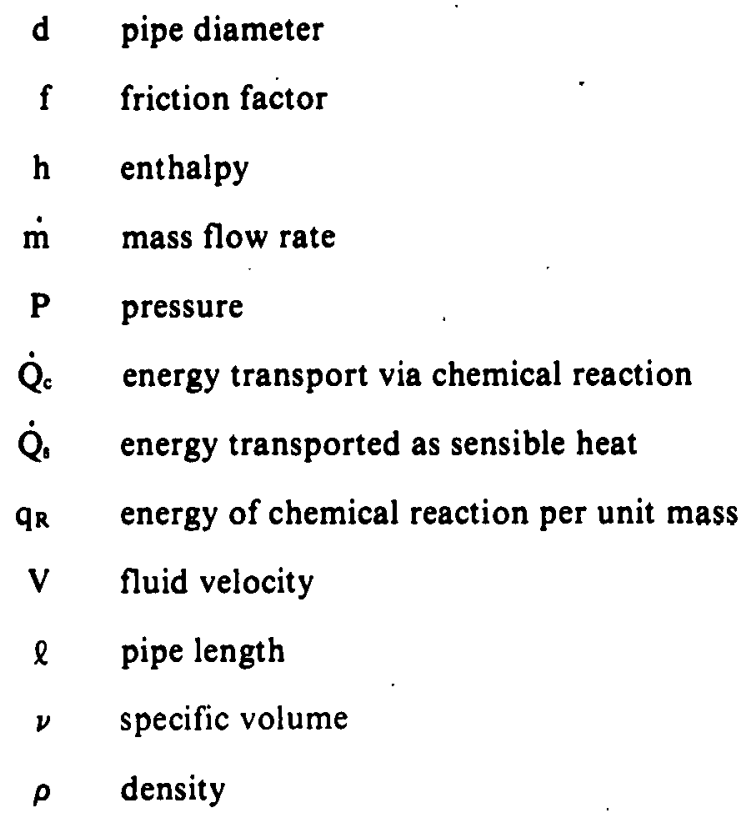




\title{
SCREENING STUDY ON HIGH TEMPERATURE ENERGY TRANSPORT SYSTEMS
}

\author{
R. L. Graves
}

\begin{abstract}
The purpose of the study described in this document is to identify the options for transporting thermal energy over long distances. The study deals specifically and exclusively with high temperature $\left[>400^{\circ} \mathrm{C}\left(752^{\circ} \mathrm{F}\right)\right]$ energy for industrial use. Energy transport is seen as a potential solution to:

1. high unit cost of small coal and nuclear steam generators,

2. opposition to siting of coal or nuclear plants near populated areas.

The study is of a preliminary nature but covers many options including steam, molten salts, organics, and chemical heat pipes. The development status and potential problems of these and other energy transport methods are discussed.

Energy transport concepts are compared on a fundamental level based on physical properties and also are subjected to an economic study. The economic study indicated that the chemical heat pipe, under a specific set of circumstances, appeared to be the least expensive for distances greater than about $32 \mathrm{~km}$ ( 20 miles). However, if the temperature of the energy was lowered, the heat transfer salt (sodium nitrate/nitrite) system would apparently be a better economic choice for.less than about $80 \mathrm{~km}$ ( 50 miles). None of the options studied appear to be more attractive than small coal-fired boilers when the transport distance is over about $64 \mathrm{~km}$ (40 miles). Several recommendations are made for refining the analysis.
\end{abstract}

\section{INTRODUCTION}

Industry in the United States accounts for about $18 \%$ of the nation's oil consumption and about $42 \%$ of the natural gas consumption.' End uses of these fuels in industry include steam raising, process heating, combustion for power, and feedstocks. The relative magnitudes of the fuel consumptions for these end uses have been difficult to quantify, but the distribution in Table 1 is believed to be fairly representative of the situation.

Table 1. End uses of oil and natural gas in the industrial sector

(\%)

\begin{tabular}{lr}
\hline Steam generation & 39 \\
Direct fired heaters & 35 \\
Combustion engines & 3 \\
Non-fuel uses & 23 \\
\hline
\end{tabular}


Although other energy sources such as coal and nuclear are suitable for these end uses (especially steam generation), economics in the past have given rise to the current energy use pattern characterized by the widespread use of oil and natural gas.

The disproportionate increases in crude oil prices and the possibility of occasional disruption of supply have indicated that a wiser energy use pattern would be that industry rely more heavily on coal or nuclear energy in order to conserve oil and natural gas for use in the transportation and residential sectors in which substitution is less feasible.

Studies have shown, however, that even with inflated oil prices, the use of coal or nuclear energy is not economically competitive unless the energy producing plants are quite large, about $350 \mathrm{MWt}$ (1.2X $10^{9} \mathrm{Btu} / \mathrm{h}$ ) for example. ${ }^{2}$ This scale effect on the economics of energy production is clearly evident in Fig. 1. Since the majority of ind ustrial plants consume less than $150 \mathrm{MWt}\left(0.6 \times 10^{9} \mathrm{Btu} / \mathrm{h}\right)$ in the form of steam ${ }^{2}$ it is necessary in most cases that a single large reactor or coal-fired plant serve more than one ind ustrial site, thus giving rise to the need for transporting thermal energy. The same need arises from siting problems for large power plants. Continuing public apprehensıon toward nuclear energy will

ORNL-DWG 80.4342 ETD

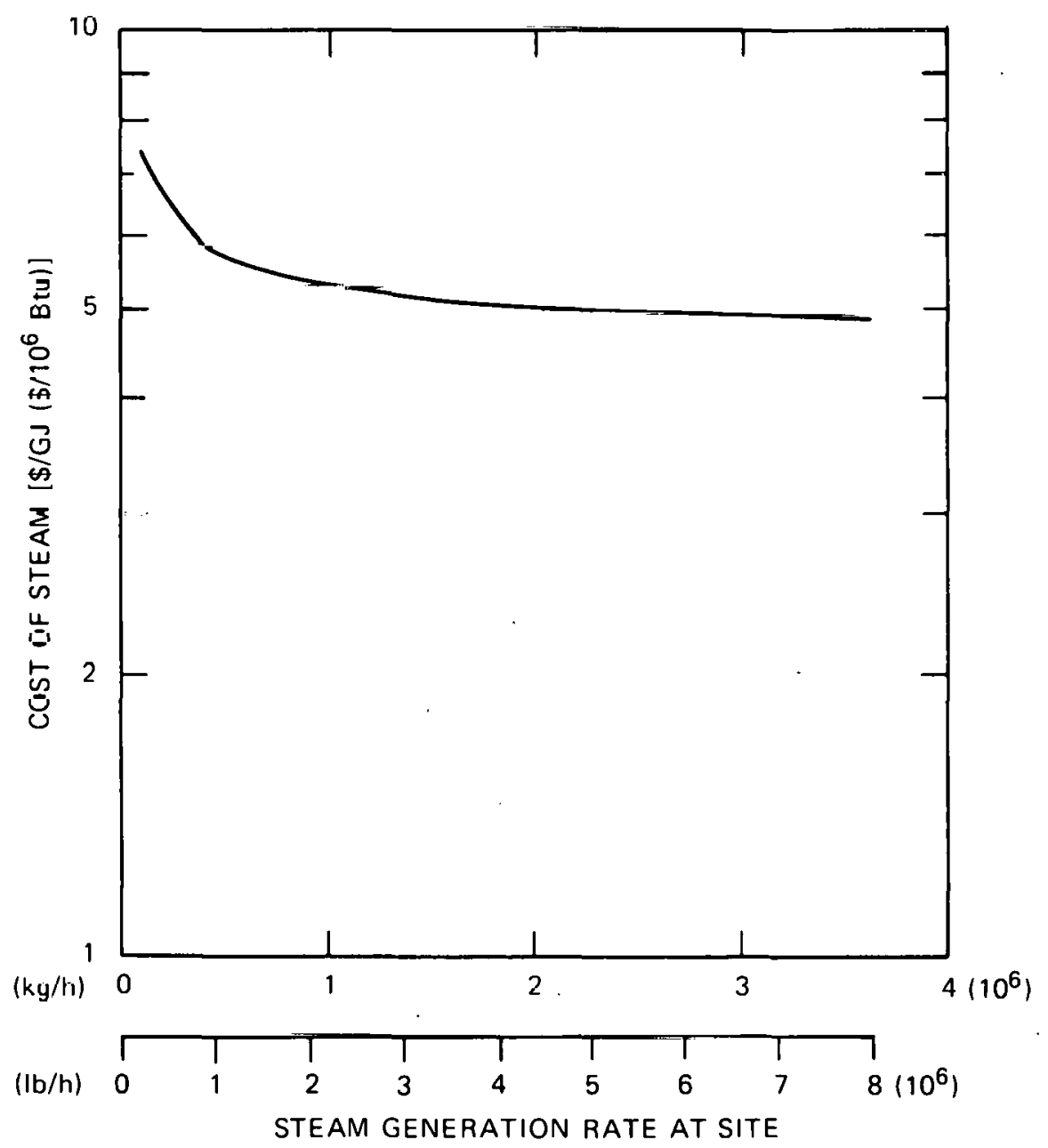

Fig. 1. Effect of boiler installation size on cost of steam from coal firing. 
most likely force these energy plants further from populated areas. Furthermore, even though combustion technology is steadily improving, the presence of coal and ash piles is not likely to be tolerated in close proximity to residential areas. Hence, movement of thermal energy is seen as a possible solution to, at least, these two problems of economics and siting.

For moving energy at moderate temperatures $\left[180^{\circ} \mathrm{C}\left(356^{\circ} \mathrm{F}\right)\right]$ and short distances $[8 \mathrm{~km}(5 \mathrm{mile})]$, steam and hot water have been generally accepted and proven as satisfactory media. ${ }^{3}$ These conventional media become less attractive as the temperature of the transported energy is increased. Although not so in all types of industry, there is substantial use of high pressure steam in petroleum refineries, pulp and paper manufacturing, and to a lesser degree in the chemical industry. Substantiating information is presented in Table 2.

Table 2. Steam generation in petroleum refining, chemical, and paper/pulp industries

\begin{tabular}{lc}
\hline & $\begin{array}{c}\text { Steam generated at } \\
>3.1 \mathrm{MPa}(450 \mathrm{psi}) \\
(\%)\end{array}$ \\
\hline Petroleum refining industry & 80 \\
Chemical industry & 48 \\
Paper/pulp industry & 73 \\
\hline
\end{tabular}

Source: A Study of Inplant Electric Power Generation in the Chemical, Petroleum Refining and Paper and Pulp Industries, TE5429-97-76, ThermoElectron Corp., 1976.

It becomes apparent, then, that if most of industry's energy needs are to be satisfied through utilization of coal or nuclear sources, methods for transporting high temperature energy across potentially larger distances are necessary.

Numerous concepts and media have been studied or are being studied for their potential in transporting high temperature energy. Basically, however, all fall into categories of electrical energy, sensible/latent heat, and chemical energy. Discussion and analysis of representative concepts in these categories are presented in the following sections of this report.

Generally in this study the analyses are limited to the heat transport system exclusive of the devices employed to generate the thermal energy or the reactors or heat exchangers required to transfer the energy from its source to the transport system. Appropriate attention is provided in cases where the heat exchanger equipment plays a more significant role in the cost of moving the thermal energy.

The basic purpose of this study is to examine the various concepts for transport of high temperature energy and to screen out concepts which appear to have little potential. On the other hand, research and development efforts which would enhance the implementation of promising energy transport concepts are to be identified as well. 


\section{IDENTIFICATION OF CONCEPTS FOR MOVING \\ THERMAL ENERGY}

\section{Electricity}

Electric power can be transmitted via underground or overhead high voltage wires over very long distances. Industrial use of electricity for heat is significant in a few industries such as electric steel making. Aluminum production and the manufacture of chlorine require large amounts of electricity also, but for electrolytic processes.

Electricity is used to generate steam in electrode boilers which are usually small in capacity. The largest units a vailable are on the order of $50 \mathrm{MWt}^{4}$ and can supply steam at up to $4.4 \mathrm{MPa}$ (600 psi). Electricity used for steam generation in industry is not a significant part of the overall industrial energy consumption.

The relatively high cost of the equipment required to generate electric power and the low overall efficiency of converting primary fuels to electricity $(\approx 32 \%)$ have generally made electricity a poor economical choice for heating. The industrial heat pump has the potential for improving the overall efficiency thus improving the economics. Heat pumps for industrial applications are currently manufactured and sold by Westinghouse Electric Corporation.

\section{Sensible and Latent Heat Media}

Sensible and latent heat media described here are all fluids intended to be transported through pipelines. In schematic form, the transport of such media appears quite simple (Fig. 2). Although oil and natural gas are generally the most economical means for transporting energy via pipelines, it is reiterated here that the interest is in the conversion to coal or nuclear energy sources for heat.

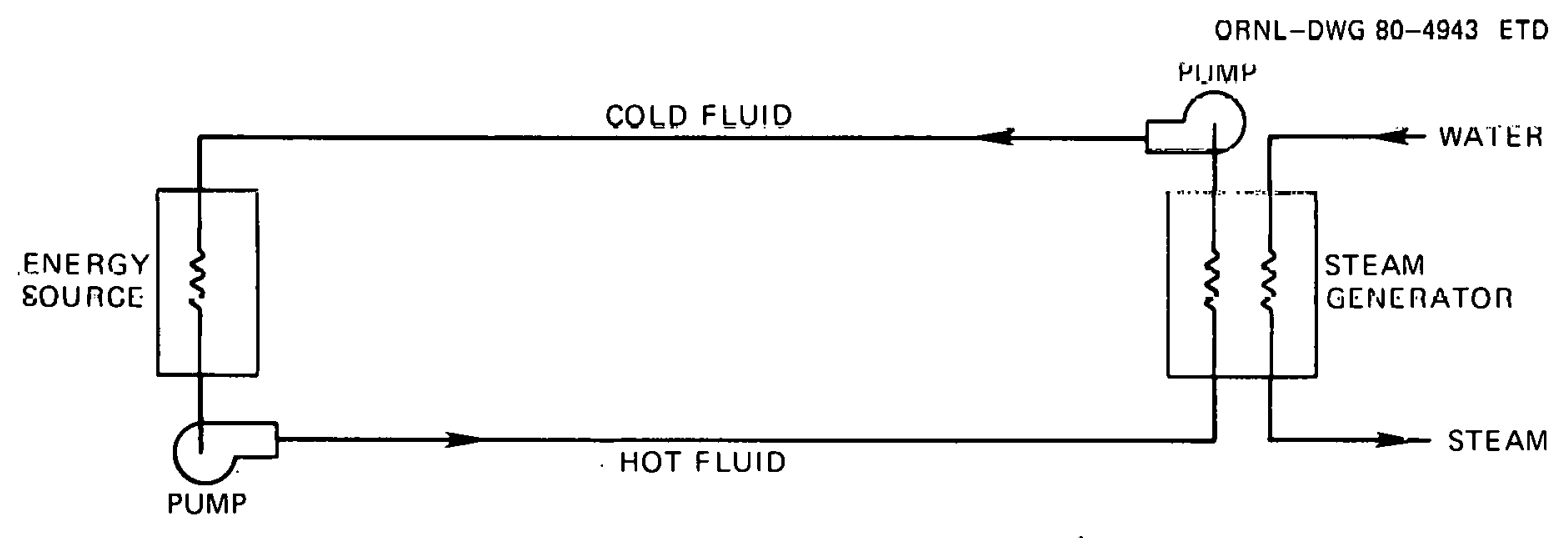

Fig. 2. Simple schematic of sensible or latent heat energy transport system.

\section{Steam}

Steam is one of few latent heat media which can be used for transport of high temperature energy. Materials limitations have generally limited steam temperatures to $538^{\circ} \mathrm{C}\left(1000^{\circ} \mathrm{F}\right)$ for the last 25 years. The latent heat of steam, of course, provides significant improvement in energy transport per unit volume over gaseous sensible heat media such as air. 


\section{Water}

Sensible heat media in liquid form are attractive due to their high energy per unit volume. Water is one of the better media due to its high heat capacity, materials compatibility, low cost, etc. However, water cannot be used for heat transport at over its critical temperature, about $374^{\circ} \mathrm{C}\left(705^{\circ} \mathrm{F}\right)$, and the saturation pressure at this point has been shown to be far higher than economically feasible. Recent studies have shown water to be a suitable option at heat delivery temperatures of $150^{\circ} \mathrm{C}\left(300^{\circ} \mathrm{F}\right)$ or less. ${ }^{3}$

\section{Molten salts}

The term "molten salts" encompasses a very large number of candidate media. Due to heavy involvement in molten salt reactor (MSR) development, the Oak Ridge National Laboratory (ORNL) has compiled and generated numerous documents on such materials. A list of identified salt coolants for the MSR is shown in Table 3. Molten salts have not been evaluated to any significant extent for the long distance transport of high temperature thermal energy. There are other salts, such as haloaluminates, which have been identified but for which information is very limited. A version of the nitrate salt is currently marketed by Coastal Chemical Company under the name of Hitec and its use is scattered throughout the industrial sector.

Operating experience with lithium and beryllium flourides has been gained in MSR experiments as well as sodium fluoride-sodium fluoroborate mixtures in experiments related to MSR development. ${ }^{5}$

Table 3. Molten salt heat transport media

\begin{tabular}{|c|c|c|}
\hline Designation & Composition mole \% & $\begin{array}{c}\text { Melting } \\
\text { temperature } \\
{\left[{ }^{\circ} \mathrm{C}\left({ }^{\circ} \mathrm{F}\right)\right]}\end{array}$ \\
\hline NA BF4-NA F & $92 \mathrm{NaBF}_{4}, 8 \mathrm{NaF}$ & $385(725)$ \\
\hline LI F--BE F2 & $66 \mathrm{LiF}, 34 \mathrm{BeF}_{2}$ & $458(856)$ \\
\hline FLINAK & $46.5 \mathrm{LiF}, 11.5 \mathrm{NaF}, 42.0 \mathrm{KF}$ & $455(851)$ \\
\hline NA+K F--ZR F4 & $10.0 \mathrm{NaF}, 48.2 \mathrm{KF}, 42.0 \mathrm{ZrF}_{4}$ & $385(725)$ \\
\hline NA $\emptyset \mathrm{H}$ & $100 \mathrm{NaOH}$ & $159(318)$ \\
\hline LI CL-K CL & $59.0 \mathrm{LiCl}, 41.0 \mathrm{KCl}$ & $360(680)$ \\
\hline NITRATES & $6.9 \mathrm{NaNO}_{3}, 48.5 \mathrm{NaNO}_{2}, 44.6 \mathrm{KNO}_{3}$ & $142(288)$ \\
\hline LMP FLUORIDES & 35.0 LiF, 27.0 NaF, 38.0 $\mathrm{BeF}_{2}$ & $338(640)$ \\
\hline CARB $\emptyset N A T E S$ & $43.5 \mathrm{Li}_{2} \mathrm{CO}_{3}, 31.5 \mathrm{Na}_{2} \mathrm{CO}_{3}, 25.0 \mathrm{~K}_{2} \mathrm{CO}_{3}$ & $397(747)$ \\
\hline
\end{tabular}

\section{Liquid metals}

The candidate liquid metals for heat transport include several alkali metals, lead and bismuth, and mercury. Although the alkali metals have ideal characteristics of low melting point and low vapor pressure at high temperatures, their reactivity with water and combustibility in air make them somewhat of an environmental risk for pipeline transport. Lead and bismuth have rather high melting points, thus reducing their attractiveness. Mercury can be essentially eliminated from further consideration due to its toxicity and cost. The media described above are listed in Table 4.

\section{Organics and silicons}

A multitude of organic or silicon-based fluids are available as energy transport media or at least have been investigated for the purpose. The maximum utilization temperature of these materials is 
Table 4. Liquild metal heat transport media

\begin{tabular}{llc}
\hline Name & $\begin{array}{c}\text { Composition } \\
\text { (weight \%) }\end{array}$ & $\begin{array}{r}\text { Melting point } \\
{\left[{ }^{\circ} \mathrm{C}\left({ }^{\circ} \mathrm{F}\right)\right]}\end{array}$ \\
\hline Sodium & $100 \mathrm{Na}$ & $98(208)$ \\
NaK & $44 \mathrm{~K}, 56 \mathrm{Na}$ & $19(66)$ \\
Bismuth & $100 \mathrm{Bi}$ & $271(520)$ \\
PB--BI & $55 \mathrm{Bi}, 45 \mathrm{~Pb}$ & $125(257)$ \\
Mercury & $100 \mathrm{Hg}$ & $-39(-38)$ \\
Lead & $100 \mathrm{~Pb}$ & $327(621)$ \\
Potassium & $100 \mathrm{~K}$ & $28(83)$ \\
\hline
\end{tabular}

almost universally limited to less than $425^{\circ} \mathrm{C}\left(795^{\circ} \mathrm{F}\right)$. A list including most of the available organictype media is provided in l'able $b$.

The use of the fluids is not uncommon among the process industries. ${ }^{6}$ Organics have also been used and evaluated as coolant-moderators in nuclear reactors. ${ }^{7}$ The cited advantages for organics include low vapor pressure at high temperatures and low corrosion rates with conventional materials. Flammability and heat transfer coefficients lower than those for water are the apparent disadvantages other than the temperature limit for utilization.

Table 5. Organic heat transport media

\begin{tabular}{|c|c|c|c|}
\hline Name & Composition & $\begin{array}{c}\text { Temperature range } \\
{\left[{ }^{\circ} \mathrm{C}\left({ }^{\circ} \mathrm{F}\right)\right]}\end{array}$ & Principal usage \\
\hline Dowtherm $\mathrm{E}^{a}$ & o-Dichlorobenzene & -18 to $260(0$ to 500$)$ & Vapor 180 to $260^{\circ} \mathrm{C}$ \\
\hline Dowtherm $\mathbf{H}^{a}$ & Aromatic vil & -9 to $288(15$ to 550$)$ & Liquid \\
\hline Dowtherm $\mathbf{J}^{a}$ & Alkylated aromatic & -73 to $302(-100$ to 575$)$ & Vapor 181 to $302^{\circ} \mathrm{C}$ \\
\hline Dowtherm $\mathrm{G}^{\circ}$ & Di- and tri-aryl ethers & -11 tọ $343(12$ to 650$)$ & Liquid \\
\hline Dowtherm $A^{o}$ & $\begin{array}{l}\text { Eutectic mixture of diphenyl } \\
\text { and diphenyl oxide }\end{array}$ & 16 to $399(60$ to 750$)$ & Vapor 257 to $399^{\circ} \mathrm{C}$ \\
\hline Humble therm $500^{b}$ & Aliphatic oil & -21 to $316(-5$ to 600$)$ & Liquid \\
\hline Mobiltherm $600^{\circ}$ & Alkylated aromatic & -21 to $316(-5$ to 600$)$ & Liquid \\
\hline Therminol $44^{d}$ & Modified ester & -51 to 218 ( -60 to 425$)$ & Liquid \\
\hline Therminol $55^{d}$ & Alkylated aromatic & -18 to $316(0$ to 600$)$ & Liquid \\
\hline Therminol $60^{\circ}$ & Aromatic hydrocarbon & -51 to $316(-60$ to 600$)$ & Liquid \\
\hline 1 herminol $60^{d}$ & Modified terphenyi & -7 to $343(20$ to 650) & Llquild \\
\hline Therminol $88^{d}$ & Mixed terphenyl & 145 to 427 (293 to 800$)$ & Liquid \\
\hline$U \operatorname{con} 50-\mathrm{HB}-280 \mathrm{X}^{c}$ & Ether of poly-alkylene oxide & -18 to $260(0$ to 500$)$ & Liquid \\
\hline Hydrotherm $750-210^{\circ}$ & Mixed aryl-arylaryloxy-silane & -18 to $399(0$ to 750$)$ & Liquid \\
\hline
\end{tabular}

${ }^{a}$ Manufactured by Dow Chemical Company.

${ }^{b}$ Manutactured by Humble Uil and Ketıning Lompany.

"Manufactured by Mobil Oil Company.

${ }^{d}$ Manufactured by Monsanto Company, marketed as Santotherm in some countries.

'Manufactured by Union Carbide Corporation.

${ }^{f}$ Manufactured by American Hydrotherm Corporation.

Source: J. L. Fried, Heat Transfer Agentsfor High-Temperature Systems, Chemical Engineering, May 28, 1973. 


\section{Chemical Reaction Heat Pipes}

The chemical heat pipes (CHP) transport thermal energy in the form of a heat of reaction of a reversible chemical reaction. Energy is absorbed via an endothermic reaction at the location of the energy source. The products of this reaction are carried in a pipeline to a location where the reaction is made to go in the opposite direction, exothermically, providing heat to a steam generator, for instance. A schematic illustration of a CHP is shown in Fig. 3.

ORNL-DWG 80-4944 ETD

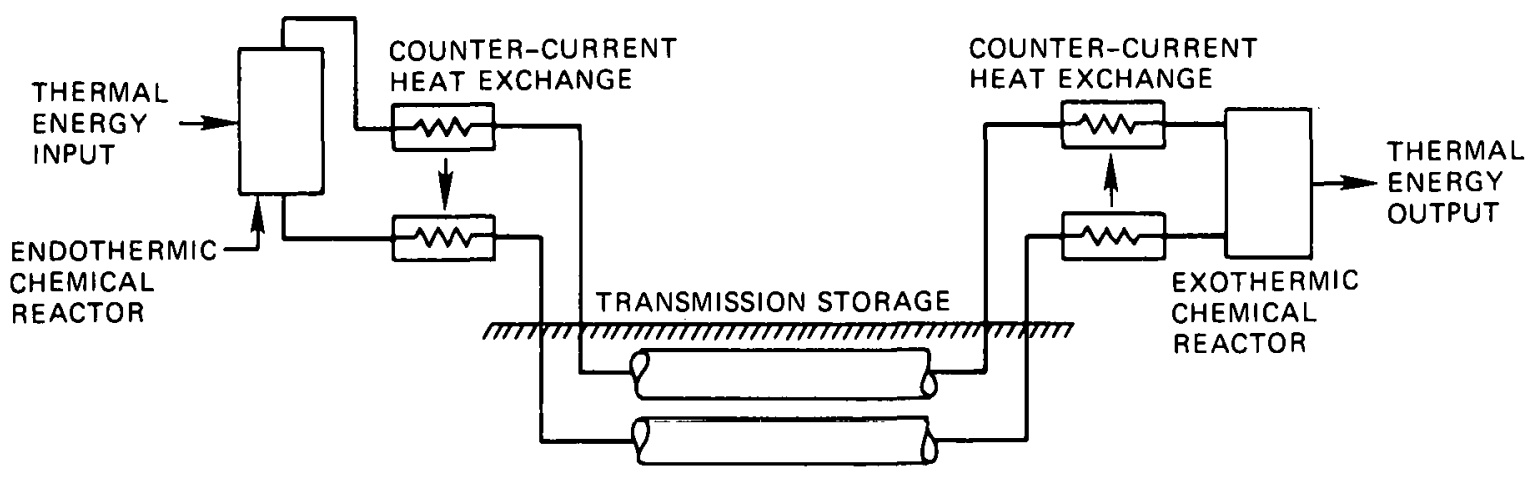

Fig. 3. CHP concept. Source: H. B. Vakil et al., Closed Loop Chemical Systems for Energy Storage and Transmission, COO-2676-1 (February 1978).

The foremost advantage of moving energy in this manner is that the reactants are transported at low temperature, hence the loss of energy during transport should be much lower than a sensible heat pipeline, and common pipe materials are sufficient. In addition, several reversible reactions are capable of delivering energy at greater than $480^{\circ} \mathrm{C}\left(896^{\circ} \mathrm{F}\right)$. An apparent disadvantage is the complexity of chemical reactors involving catalysts which are inclined to result in high cost and more difficult operation.

The reactions considered in this study are only those which involve liquid and gaseous phases. A multitude of other reactions have been identified which incorporate a solid constituent, but these systems are viewed as more suitable for energy storage rather than transport. Reactions which have been identified for energy transport are shown in Table 6. Detailed computerized schemes have been utilized to arrive at potential CHP reactions, but relatively few, as shown in Table 6, are even remotely suited to this application.

Some of the CHP concepts (and designations) currently receiving attention are:

1. $\mathrm{CO}+3 \mathrm{H}_{2} \rightarrow \mathrm{CH}_{4}+\mathrm{H}_{2} \mathrm{O}$ (EVA-ADAM)

2. $\mathrm{N}_{2}+3 \mathrm{H}_{2} \longrightarrow 2 \mathrm{NH}_{3}$ (Ammonia)

3. $\mathrm{C}_{6} \mathrm{H}_{6}+3 \mathrm{H}_{2} \longrightarrow \mathrm{C}_{6} \mathrm{H}_{12}$ (Benzene/Cyclohexane)

4. $S \Omega_{3}+1 / 2 \Omega_{3} \longrightarrow s \Omega_{3}$ (Snlchem)

Additional comments on these candidate reactions follow. 
Table 6. Candidate reactions for chemical heat pipe systems excluding those reactions containing solids

\begin{tabular}{|c|c|c|c|}
\hline \multirow{2}{*}{$\frac{\begin{array}{c}\text { Reaction } \\
\text { exothermic }\end{array}}{\text { endothermic }}$} & \multirow{2}{*}{$\begin{array}{c}\text { Reaction enthalpy } \\
\text { at } 298 \mathrm{~K}\left(77^{\circ} \mathrm{F}\right) \\
{[\mathrm{J} / \mathrm{g}(\mathrm{Btu} / \mathrm{lb})]}\end{array}$} & \multicolumn{2}{|c|}{ Temperature (K) at which } \\
\hline & & $90 \%$ formed & $90 \%$ dissociated \\
\hline $\mathrm{CO}(\mathrm{G}) । 3 \mathrm{II}_{4}(\mathrm{G}) \quad \mathrm{CII}_{4}(\mathrm{G}) \backslash \mathrm{II}_{2} \mathrm{O}(\mathrm{L})$ & $7,345(0,160)$ & & \\
\hline $\mathrm{CO}(\mathrm{G})+3 \mathrm{H}_{2}(\mathrm{G})-\mathrm{C} \cdot \mathrm{H}_{4}(\mathrm{G})+\mathrm{H}_{2} \mathrm{O}(\mathrm{G})$ & $6,053(2,604)$ & 754 & 1,466 \\
\hline $\mathrm{C}_{2} \mathrm{H}_{4}(\mathrm{G})+\mathrm{H}_{2}(\mathrm{G}) \rightarrow \mathrm{C}_{2} \mathrm{H}_{6}(\mathrm{G})$ & $4,561(1,962)$ & 841 & 1,205 \\
\hline $2 \mathrm{CO}(\mathrm{G})+2 \mathrm{H}_{2}(\mathrm{G})-\mathrm{CH}_{4}(\mathrm{G})+\mathrm{CO}_{2}(\mathrm{G})$ & $4,118(1,772)$ & 778 & 1,152 \\
\hline $\mathrm{CO}(\mathrm{G})+2 \mathrm{H}_{2}(\mathrm{G})-\mathrm{CH}_{3} \mathrm{OH}(\mathrm{L})$ & $3,996(1,718)$ & 345 & 434 \\
\hline $\mathrm{N}_{2}(\mathrm{G})+3 \mathrm{H}_{2}(\mathrm{G}) \rightarrow 2 \mathrm{NH}_{3}(\mathrm{~L})$ & $3,861(1,661)$ & & \\
\hline $\mathrm{N}_{2}(\mathrm{G})+3 \mathrm{H}_{2}(\mathrm{G})-2 \mathrm{NH}_{3}(\mathrm{G})$ & $2,695(1,159)$ & 346 & 528 \\
\hline $2 \mathrm{NO}_{(\mathrm{G})}+\mathrm{O}_{2}(\mathrm{G}) \rightarrow \mathrm{N}_{2} \mathrm{O}_{4}(\mathrm{~L})$ & $1,750(753)$ & 549 & 930 \\
\hline$S Q_{r}(\mathrm{G})+\mathrm{Air}-\mathrm{SO} \mathrm{O}_{(\mathrm{G})^{a}}$ & 1,544 (f.d4) & 806 & 1,270 \\
\hline$s n_{2}(!)+l_{1} \Omega_{1}(G)-\$ \Omega_{1}(L)$ & $1.517(653)$ & 783 & 1,235 \\
\hline $\mathrm{SO}_{2}(\mathrm{G})+1 / 2 \mathrm{O}_{2}(\mathrm{G}) \rightarrow \mathrm{SO}_{3}(\mathrm{G})$ & $1,235(531)$ & 792 & 1,235 \\
\hline $\mathrm{NO}(G)+1 / 2 \mathrm{O}_{2}(\mathrm{G})-\mathrm{NO}_{2}(\mathrm{G})$ & $1 ; 213(535)$ & 549 & 930 \\
\hline $\mathrm{CO}(\mathrm{G})+\mathrm{Cl}_{2}(\mathrm{~L}) \rightarrow \mathrm{COCl}_{2}(\mathrm{~L})$ & $1,172(504)$ & 628 & 881 \\
\hline $\mathrm{NO}_{2}(\mathrm{G})+\mathrm{NO}_{2}(\mathrm{G})-\mathrm{N}_{2} \mathrm{O}_{2}(\mathrm{~L})$ & $932(401)$ & 288 & 381 \\
\hline $\mathrm{SO}_{3}(\mathrm{~L})+\mathrm{H}_{2} \mathrm{O}(\mathrm{L}) \rightarrow \mathrm{H}_{2} \mathrm{SO}_{4}(\mathrm{~L})$ & $885(381)$ & 535 & 723 \\
\hline $\mathrm{SO}_{2}(\mathrm{G})+\mathrm{Air} \rightarrow \mathrm{SO}_{3}(\mathrm{G})$ & $727(313)$ & 806 & 1,270 \\
\hline $\mathrm{NO}(\mathrm{G})+1 / 2 \mathrm{Cl}_{2}(\mathrm{~L}) \rightarrow \mathrm{NOCl}(\mathrm{L})$ & $695(299)$ & 425 & 819 \\
\hline $\begin{array}{l}\mathrm{H}_{2} \mathrm{O}(\mathrm{L})+\mathrm{H}_{2} \mathrm{SO}_{2}(\mathrm{~L})-\mathrm{H}_{2} \mathrm{SO}_{4} \cdot \mathrm{H}_{2} \mathrm{O}(\mathrm{L}) \\
\text { For comparison: }\end{array}$ & $230(99)$ & & \\
\hline $\mathrm{H}_{2}(\mathrm{G})+1 / 2 \mathrm{O}_{2}(\mathrm{G})-\mathrm{H}_{2} \mathrm{O}(\mathrm{G})$ & $13,423(5,775)$ & 2,830 & 5,600 \\
\hline
\end{tabular}

${ }^{a}$ Based on $\mathrm{SO}_{2}$ weight only. Air open cycle.

Source: E. W. Schmidt, Thermochemical Energy Storage Systems, Proceedings of the Eleventh Intersociety Energy Conversion Engineering Conference, September 12-17, 1976.

\section{EVA-ADAM}

The abbreviations EVA and ADAM refer to the reformer and methanator chemical reastors, respectively, of this transport system. "EVA" is formed by abbreviating the German term for steam reformer tube, and ADAM was chosen as an analogous supplement to identify the methanator. The reaction has been studied and developed for transport of nuclear energy over long distances at the Nuclear Research Center, Jülich, Germany, since the early 1970s. ${ }^{8}$

The reaction's capability for delivering high temperature energy is attractive, as is the fact that the water used or produced in the reactions need not be transported and may be condensed out of the gaseous constituents, thus reducing the mass which must be carried in the pipelines. Both reactions require catalysts. Note that this reaction also is among the highest in energy density (see Table 6).

An open-loop variation of this $\mathrm{CHP}$ has been investigated by the Institute of Gas Technology (IGT). ${ }^{9}$ In this system methane (natural gas) would be steam reformed to $\mathrm{CO}$ and $\mathrm{H}_{2}$, by nuclear or coal-fired prime energy. These constituents would be transported and converted back to methane, recovering the chemical energy, and then the methane would be burned as fuel.

\section{Ammonia}

Ammonia decomposition can be used for transport of high temperature energy if the reaction pressure is about $30 \mathrm{MPa}(300 \mathrm{~atm})$. Even at this pressure, however, the fraction $\mathrm{N}_{2} /\left(\mathrm{N}_{2}+\mathrm{NH}_{3}\right)$ is only 
reduced to about 0.31 at $450^{\circ} \mathrm{C}\left(842^{\circ} \mathrm{F}\right) .10$ The ammonia $\mathrm{CH} P$ can incorporate a liquid phase transport pipeline carrying the ammonia under moderate pressure, about $1.0 \mathrm{MPa}$ (10 atm). Ammonia decomposition and synthesis is a well-developed and well-understood technology.

Cyclohexane/benzene. The dehydrogeneration of cyclohexane received serious attention recently in a systems study performed by GE under subcontract to Sandia Laboratories for DOE." This CHP is similar to EVA-ADAM in energy density but operates in a slightly lower temperature band. The lack of development efforts on high temperature reactors (HTR) in the United States prompted this activity in lower temperature heat pipes. A cursory inspection reveals that unlike the EVA-ADAM CHP, the cyclohexane/benzene system offers no opportunity to condense part of the reactants for reduced mass flow via pipeline. The reaction and catalysts for this heat pipe concept are not developed to a level sufficient for the application.

Solchem. The $\mathrm{SO}_{2} / \mathrm{SO}_{3} \mathrm{CHP}$ is being studied as a solar powered chemical reaction loop (hence solchem) either for transport or storage of energy for high temperature needs. ${ }^{12-13}$ As an energy transport media, $\mathrm{SO}_{3}$ can be liquified but only in a very narrow temperature range, $32.5-44.8^{\circ} \mathrm{C}$ $\left(90-113^{\circ} \mathrm{F}\right)^{14}$ at atmospheric pressure. Sulfur trioxide is an extremely hazardous material reacting violently with water and releasing clouds of sulfuric acid vapor when spilled. This $C H P$ would require a rather high temperature energy source and its energy density is much lower than the EVA-ADAM system (see Table 6). The suitability of commercial catalysts for a CHP operation has not been clarified. 


\section{FUNDAMENTAL COMPARISON OF ENERGY TRANSPORT CONCEPTS}

In lieu of initiating a broad-based design and economic study, a preliminary study using fundamental physical and economic relations was performed to compare various concepts for energy transport. The physical relations involve pressure, flow, and energy transport properties.

Friction pressure drop in pipelines can be expressed as

$$
\Delta P \propto \frac{f l}{d} \rho V^{2}
$$

where the velocity is determined from

$$
\mathrm{V}=\frac{4 \dot{\mathrm{m}} \nu}{\pi \mathrm{d}^{2}}
$$

The energy transport for sensible and latent heat media is defined as the enthalpy change at the point of heat delivery, i.e., the media enthalpy drop at the steam generator. For a CHP the energy is the exothermic heat of reaction.

For sensible or latent system the total energy transfer is

$$
\dot{\mathrm{Q}}_{\mathrm{s}}=\dot{\mathrm{m}} \Delta \mathrm{h}
$$

and for the $\mathrm{C} H \mathrm{H}$

$$
\dot{\mathrm{Q}}_{\mathrm{c}}=\dot{\mathrm{mq}}_{\mathrm{R}} \text {. }
$$

Substituting these relations into Eq. (1), the pressure drop becomes

$$
\Delta \mathbf{P} \propto \frac{\mathrm{f} \ell \nu \dot{\mathrm{Q}}^{2}}{\mathrm{~d}^{5}(\Delta \mathrm{h})^{2}}
$$

where $\Delta \mathrm{h}$ and $\mathrm{q}_{\mathrm{H}}$ are Interchangeable.

To arrive at an index for energy transport economics, first rearrange Eq. (3),

$$
\mathrm{Q} \propto\left(\frac{\Delta \mathrm{Pd}^{5} \Delta \mathrm{h}^{2}}{\mathrm{f} \ell_{u}}\right)^{1 / 2}
$$

Then, assuming that pipe cost is approximately proportional to the diameter squared and pressure

$$
\frac{Q}{\mathbb{S}} \ddot{Q} \frac{\mathrm{Q}}{\mathrm{d}^{2} \mathrm{P}} \propto\left(\frac{\Delta \mathrm{Pd} \Delta \mathrm{h}^{2}}{\mathrm{f} \ell \nu \mathrm{P}^{2}}\right)^{1 / 2} .
$$

Then if the further assumption is made that all fluid flows are in the fully turbulent regime, the friction factor becomes independent of the fluid flow and physical properties, thus simplifying the comparison. 
The pressure drop may also be treated as a constant, although some discrepancy in pumping power will arise since gas compression usually requires higher specific work than liquid pumping. Pipe length and diameter can also be treated as common for all transport media. The comparison index then becomes

$$
\frac{\mathrm{Q}}{\mathrm{d}^{2} \mathrm{P}} \propto\left(\frac{\Delta \mathrm{h}^{2}}{\nu \mathrm{P}^{2}}\right)^{1 / 2}
$$

By incorporating typical transport pressures for gases and liquids the index provides the results shown in Fig. 4 after referencing to methane fuel which was assigned a value of ten. The temperature of each media was set at values required for generating steam at $4.5 \mathrm{MPa}(650 \mathrm{psia})$. As anticipated, steam is not attractive as a high temperature energy transport medium from this fundamental viewpoint. Considering the attention that it has received, however, the CHP is not a dramatic improvement, especially with the realization of the expensive equipment required at each end of the pipeline. The heat transfer salt, a factor of four better than the CHP, appears to be a promising candidate in spite of the unaccounted for pipeline costs of insulation, special pipe materials, etc. Efficiencies are also not reflected by this index, although there are generally not large differences between the CHP and HTS in this respect. Distinctions of this nature, in addition to costs such as that for the medium inventory, are discerned through more detailed design studies. This fundamental approach to understanding the problem, however, may be useful as more detailed discussion on the concepts is presented in the following chapters.

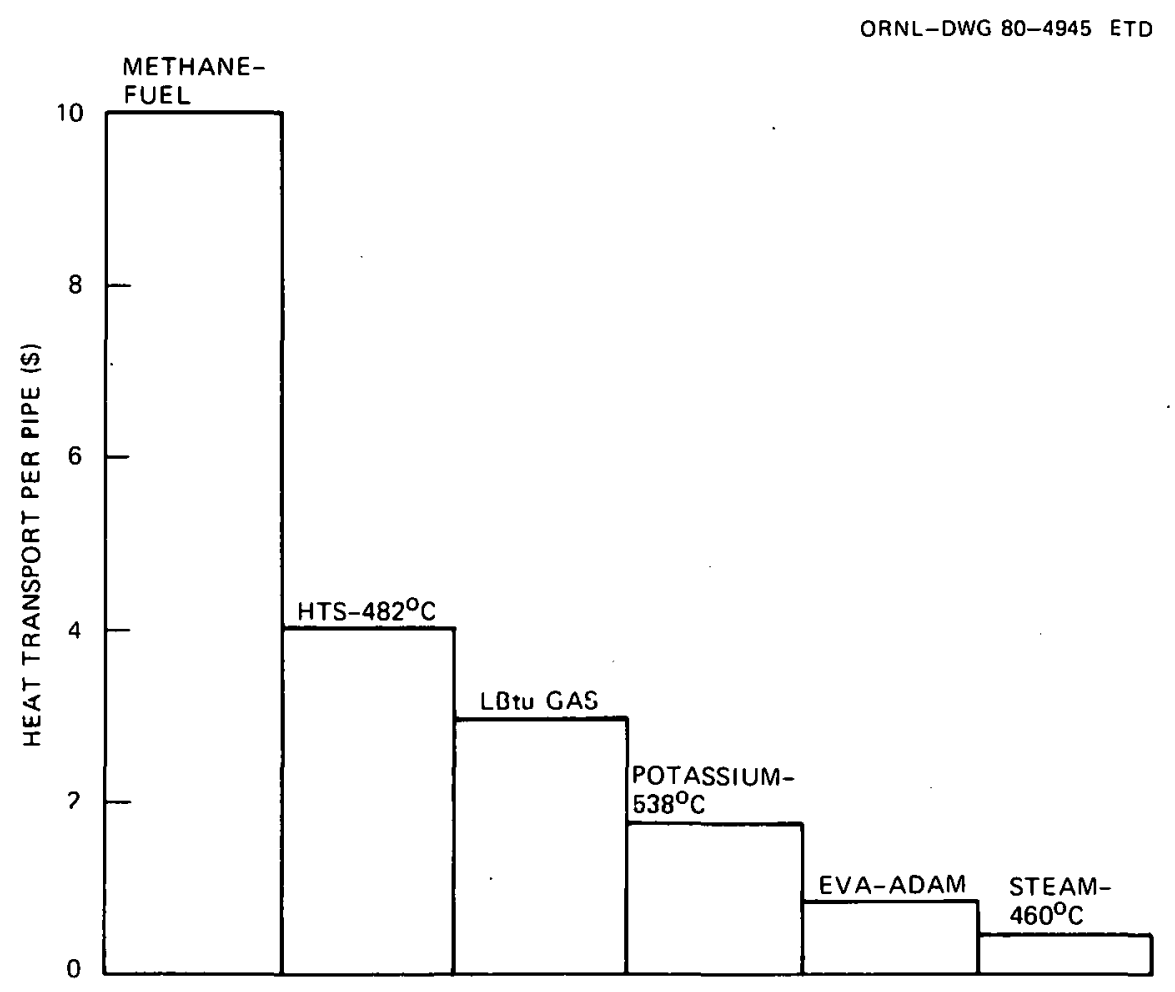

Fig. 4. Comparison of media energy transport capabilities based on fundamental parameters. 


\section{STATE OF THE ART AND ONGOING RESEARCH ON ENERGY TRANSPORT CONCEPTS}

Information describing current research and development efforts on high temperature energy transport concepts is presented in this section, in addition to an evaluation of the state of the art. The problems which are yet to be solved for some concepts are described as are the reasons for which some concepts have been dropped from consideration. The concepts receiving greatest emphasis are those identified in the previous section.

\section{Industrial Electric Heat Pump}

Since production of electric power is covered in depth in many literature outlets, only the heat pump, being a somewhat novel concept, is discussed here. Heat pumps offering a coefficient of performance (COP) of 2 or more would provide an overall efficiency in heat transport of over $60 \%$, comparable to sensible and chemical heat pipes. State-of-the-art heat pumps are limited, however, to water heating with a maximum temperature of about $104^{\circ} \mathrm{C}\left(220^{\circ} \mathrm{F}\right) .^{19}$ The source water temperature of these units must be about $38^{\circ} \mathrm{C}\left(100^{\circ} \mathrm{F}\right)$ to provide a $\mathrm{COP}$ of $2.0-2.3$. Westinghouse also markets a solar-assisted version of the industrial heat pump, but its maximum temperature is the same. A typical performance map of an industrial heat pump is shown in Fig. 5.

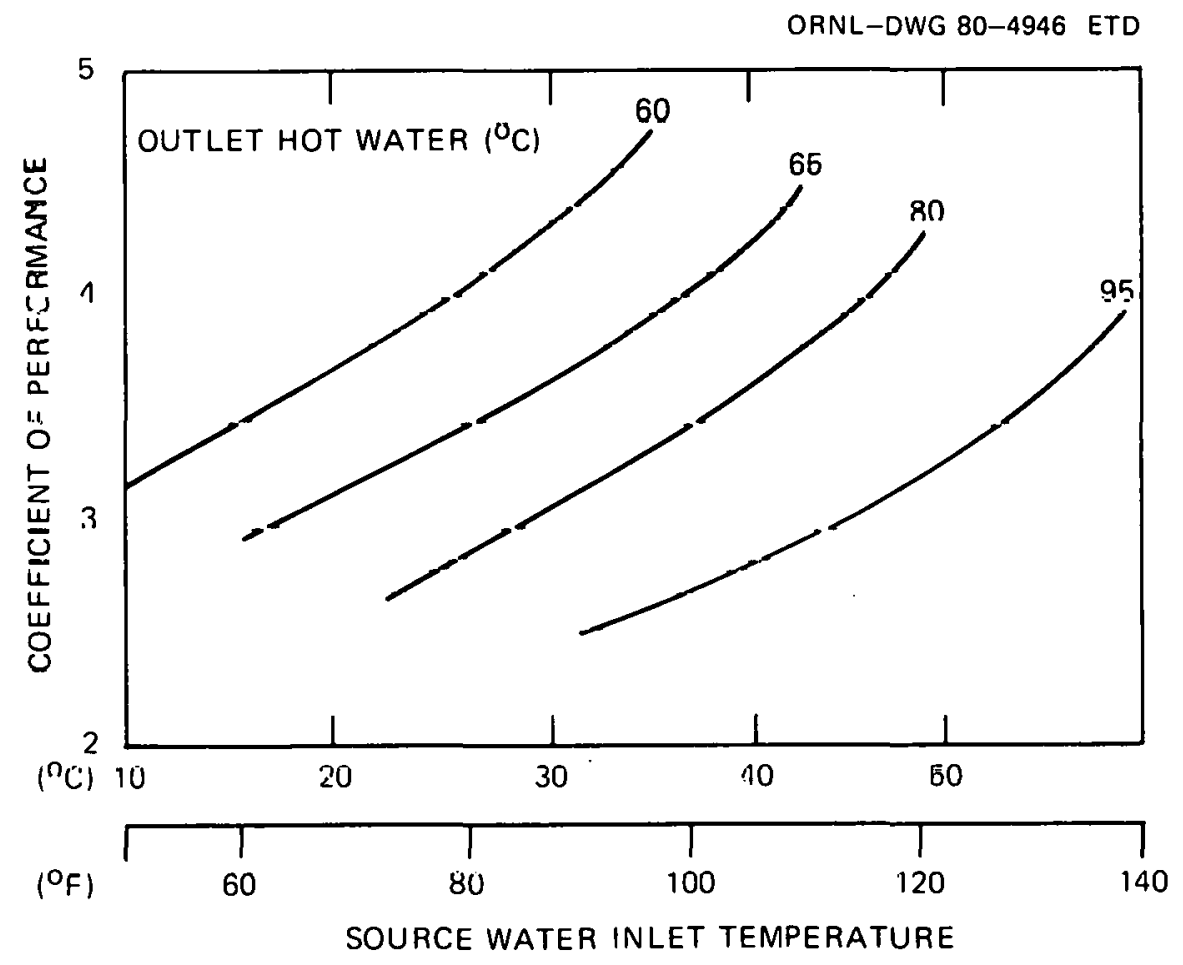

Fig. 5. Typical industrial heat pump performance. 
Extending the service of heat pumps into the $500^{\circ} \mathrm{C}\left(932^{\circ} \mathrm{F}\right)$ range might involve several alternatives:

1. development of new working fluids to extend range of vapor compression heat pumps;

2. cascading vapor compression systems using several working fluids;

3. development of alternate heat pump cycles, for example, Brayton (gas compression) and Stirling. Development efforts on vapor compression systems are not currently focused on high temperature capability.

The high temperature heat pump is faced with a genuine thermodyna mic dilemma. The COP for a reversible heat pump cycle operating between $32^{\circ} \mathrm{C}\left(90^{\circ} \mathrm{F}\right)$ and $538^{\circ} \mathrm{C}\left(1000^{\circ} \mathrm{F}\right)$ is about 1.6. If one assumes that heat pumps may be developed to the extent of large electric power plants, then it should be possible to obtain about $62 \%$ of this ideal COP, about 0.99 . Current heat pump systems operate at about $20 \%$ of the reversible cycle COP, however, and if no improvement beyond this were made the energy transport efficiency would be prohibitively low for. high temperature systems.

Additionally, the capital intensive equipment necessary for moving high temperature energy in this manner, consisting essentially of two energy conversion systems, indicates further disadvantage for the concept.

\section{Sensible and Latent Heat Media}

The experiences with sensible and latent heat media are discussed in this section, including unique advantages or problems. Hot water and steam are not treated in further detail in this section.

\section{Molten salts}

The attractiveness of molten salts for high temperature energy transport is enhanced by the following characteristics of the salt:

1. melting point $<38^{\circ} \mathrm{C}\left(100^{\circ} \mathrm{F}\right)$

2. stability at temperatures $>538^{\circ} \mathrm{C}\left(1000^{\circ} \mathrm{F}\right)$

3. noncorrosive at high temperature

4. inexpensive

5. nontoxic

6. nonflammable

7. compatible with steam

8. high specific heat capacity.

Review of the list of salts indicates a general lack of availability of low melting temperature salts. The low melting point is important since it lowers the flow required per unit of energy transport and reduces heat losses on the return leg of the closed loop. Trace heating is also mandatory on pipelines carrying salts with high melting temperatures.

Flouride salts. Flouride salts were among the class of materials studied in great depth in conjunction with the molten salt reactor development at ORNL. ${ }^{16-17}$ Flourides are generally characterized by high melting points but are also stable at temperatures of $750^{\circ} \mathrm{C}\left(1380^{\circ} \mathrm{F}\right)$ and are compatible with state-of-the-art alloys such as Inconel and Hastelloy N. ${ }^{18}$ The discussion here will emphasize those flouride salts with the lowest melting points, as shown in Table 7.

Although stannous flouride has an acceptably low liquidus temperature, it is reportedly unstable at high temperatures. ${ }^{16}$ The remaining flourides have liquidus temperatures which are high enough to make them less attractive than alternate salts. In addition, $\mathrm{LiF}$ and $\mathrm{BeF}_{2}$ are expensive and the latter is 
Table 7. Low melting temperature flouride salts

\begin{tabular}{lll}
\hline \multicolumn{1}{c}{ Salt } & $\begin{array}{c}\text { Melting } \\
\text { temperature } \\
{\left[{ }^{\circ} \mathrm{C}\left({ }^{\circ} \mathrm{F}\right)\right]}\end{array}$ & \multicolumn{1}{c}{ Common name } \\
\hline $\mathrm{LiF}-\mathrm{NaF}-\mathrm{KF}(46.5-11.5-42)$ & $454(849)$ & FLINAK \\
$\mathrm{SnF}_{2}$ & $100(212)$ & Stannous flouride \\
$\mathrm{NaF}_{\mathrm{B}} \mathrm{BeF}_{2}(57-43)$ & $360(680)$ & \\
$\mathrm{NaF}_{\mathrm{NaBF}}(8-92)$ & $384(723)$ & Sodium flouroborate \\
\hline
\end{tabular}

highly toxic. ${ }^{18}$ However, the flourides have some advantages, including high heat capacity in the range of $0.36-0.45 \mathrm{cal} / \mathrm{g} /{ }^{\circ} \mathrm{C}$. Furthermore, most of the flourides are compatible with steam, creating no vigorous chemical reactions when mixed. ${ }^{19}$ However, in the case of the flouroborate, the ingress of water into the salt increases its corrosivity due to the formation of hydrogen flouride and subsequent reactions. ${ }^{16}$ In summary, the characteristics of flouride salts which make them attractive for nuclear reactor systems (stability in radiation, high temperature stability, compatibility with fuel salt) are not generally coincident with characteristics of an attractive heat transport medium.

Hydroxide and oxide salts. Several of the oxide and hydroxide salts which should be noted are listed in Table 8.

Table 8. Hydroxide and oxide salts

\begin{tabular}{lc}
\hline \multicolumn{1}{c}{ Salt } & $\begin{array}{c}\text { Melting temperature } \\
{\left[{ }^{\circ} \mathrm{C}\left({ }^{\circ} \mathrm{F}\right)\right]}\end{array}$ \\
\hline $\mathrm{NaOH}$ & $318(604)$ \\
$\mathrm{NaOH}-\mathrm{KOH}(50-50)$ & $170(338)$ \\
$\mathrm{B}_{2} \mathrm{O}_{3}$ & $450(842)$ \\
\hline
\end{tabular}

Sodium hydroxide is abundant and inexpensive and is suitable for high temperature systems if it can be contained. This medium tends to be quite corrosive requiring high nickel or nickel-molybdenum alloys when used at elevated temperatures. The material possesses the further undesirable characteristics of being toxic and reactive with water via a highly exothermic reaction.

A 50-50 eutectic of $\mathrm{NaOH}$ and $\mathrm{KOH}$ yields a low melting point salt. This medium has a respectable heat capacity of $0.40 \mathrm{cal} / \mathrm{g}-{ }^{\circ} \mathrm{C}$ but has a corrosive nature similar to $\mathrm{NaOH}$.

Boric oxide has thermophysical properties similar to the hydroxides and has a higher melting temperature than desirable for energy transport.

Chloride salts. I hree representative and inexpensive chloride salts are listed in Table 9. The salts, in addition to high melting temperatures, have lower specific heat capacities than the other salts discussed previously, about $0.25 \mathrm{cal} / \mathrm{g}-{ }^{\circ} \mathrm{C}$.

Table 9. Chloride Salts

\begin{tabular}{ll}
\hline \multicolumn{1}{c}{ Salt } & $\begin{array}{c}\text { Melting temperature } \\
{\left[{ }^{\circ} \mathrm{C}\left({ }^{\circ} \mathrm{F}\right)\right]}\end{array}$ \\
\hline $\mathrm{NaCl}-\mathrm{MgCl}_{2}(52-48)$ & $450(842)$ \\
$\mathrm{NaCl}-\mathrm{CaCl}(48-52)$ & $500(932)$ \\
$\mathrm{NaCl}-\mathrm{KCl}(50-50)$ & $658(1216)$ \\
\hline
\end{tabular}


Hastelloy- $\mathrm{N}$ appears to be the most suitable material for containment with other nickel-based alloys perhaps being satisfactory below $538^{\circ} \mathrm{C}\left(1000^{\circ} \mathrm{F}\right)$. These salts are generally non-toxic and have low vapor pressure up to $800^{\circ} \mathrm{C}\left(1472^{\circ} \mathrm{F}\right)$.

Nitrate and nitrate salts mixtures. This class of molten salts appears to offer the highest potential for energy transport based on the criteria set forth in the first part of this section. Representative nitrate salts are listed in Table 10.

Table 10. Nitrate salts

\begin{tabular}{lll}
\hline \multicolumn{1}{c}{ Medium } & $\begin{array}{c}\text { Melting } \\
\text { temperature } \\
{\left[{ }^{\circ} \mathrm{C}\left({ }^{\circ} \mathrm{F}\right)\right]}\end{array}$ & Common name \\
\hline $\mathrm{NaNO}_{2}-\mathrm{NaNO}_{3}-\mathrm{KNO}_{3}(40-7-53)$ & $142(288)$ & HTS or Hitec \\
$\mathrm{NaNO}_{3}$ & $307(585)$ & Draw salt \\
$\mathrm{NaNO}_{3}-\mathrm{KNO}_{3}(46-54)$ & $220(428)$ & \\
\hline
\end{tabular}

Besides the low melting temperatures, these salts are attractive for energy transport because they 1. are non-reactive with water;

2. have high heat capacity, $0.37-0.44 \mathrm{cal} / \mathrm{g}-{ }^{\circ} \mathrm{C}$;

3. are nonflammable.

The materials are generally non-toxic with the exception of sodium nitrite in Hitec which can cause acute illness if ingested in large quantities ${ }^{20}$ and is a possible carcinogen with lesser doses. The upper practical temperature for these salts is about $550^{\circ} \mathrm{C}\left(1022^{\circ} \mathrm{F}\right)$ due primarily to the subsequent decomposition of the salt constituents (particularly the $\mathrm{NaNO}_{3}$ ) at higher temperatures. These salts are also relatively inexpensive and are available from a number of manufacturers including Park Chemical Company in Detroit, Michigan, and Coastal Chemical Company in Abbeville, Louisiana. Since these materials are presently used as heat transfer media, there is a substantial quantity of data on materials compatibility, handling precautions, and reactivity with common substances. ${ }^{21}$

Use of Hitec or draw salt at over $500^{\circ} \mathrm{C}\left(932^{\circ} \mathrm{F}\right)$ generally requires stainless steel piping. Even at less than $450^{\circ} \mathrm{C}\left(842^{\circ} \mathrm{F}\right)$ corrosion rates with carbon steel are rather high but are generally tolerated in chemical plants to reduce the system's initial cost. ${ }^{22}$ Bohlmann ${ }^{23}$ has summarized most of the available corrosion data and has extrapolated the results of short-term tests to obtain yearly corrosion rates. Corrosion data on stainless steels are not abundant.

Water intrusion per se does not increase corrosion rates. However, the presence of $\mathrm{Na}_{2} \mathrm{O}$ as an impurity results in the formation of $\mathrm{NaOH}$ which does indeed aggravate corrosion in stainless steel systems.

A possible advantage for these salts is their solubility in water which can provide assistance in startup and shutdown operations. The solubility also offers an alternative to trace heating or remelting in restarting flow after a freeze $=$ up.

Carbonate salts. The carbonates include another group of high melting point salts. The salts shown in Table 11 represent those with the lowest of liquidus temperatures.

The molten carbonates have received attention recently for use as electrolytes in high temperature fuel cells. ${ }^{24}$ Their specific heat capacities lie in the range of $0.33-0.40 \mathrm{cal} / \mathrm{g}-{ }^{\circ} \mathrm{C}$. Low allow steels and stainless steels as well as nickel-based alloys are compatible with carbonate systems up to temperatures 
Table 11. Low melting temperature carbonate salts

\begin{tabular}{lc}
\hline \multicolumn{1}{c}{ Medium } & $\begin{array}{c}\text { Melting } \\
\text { temperature } \\
{\left[{ }^{\circ} \mathrm{C}\left({ }^{\circ} \mathrm{F}\right)\right]}\end{array}$ \\
\hline $\mathrm{Li}_{2} \mathrm{CO}_{3}-\mathrm{Na}_{2} \mathrm{CO}_{3}-\mathrm{K}_{2} \mathrm{CO}_{3}(43.5-31.5-25)$ & $397(746)$ \\
$\mathrm{K}_{2} \mathrm{CO}_{3}-\mathrm{MgCO}_{3}(57-43)$ & $460(860)$ \\
\hline
\end{tabular}

of $650^{\circ} \mathrm{C}\left(1200^{\circ} \mathrm{F}\right)$, but experience indicating carbide formation at grain boundaries of non-stabilized 304 stainless indicates that a niobium stabilized 347 stainless steel is a better choice. ${ }^{18}$

Other salt mixtures. Only very few sulfates exhibit melting temperatures below $600^{\circ} \mathrm{C}\left(1112^{\circ} \mathrm{F}\right)$ and the specific heat capacities are lower than most of the salts previously presentied. Furthermore, the sulfates are very corrosive toward most alloys making them impractical for energy transport.

Phosphate salts are generally expensive and also have melting points over $500^{\circ} \mathrm{C}\left(932^{\circ} \mathrm{F}\right)$. Silicates and borates are perhaps less expensive but also have high melting temperatures.

Potassium cyanide has eutectics with $\mathrm{AgCN}$ and $\mathrm{CuCN}$ with melting temperatures below $300^{\circ} \mathrm{C}$ $\left(572^{\circ} \mathrm{F}\right)$, but the biological hazzard associated with these materials eliminates them from consideration.

A mixture of $69.5 \% \mathrm{NaAlCl}_{4}, 19.5 \% \mathrm{KAICl}_{4}$, and $1.0 \% \mathrm{NH}_{4} \mathrm{AlCl}_{4}$ (mole percent) has been identified as a possible MSR coolant. The mixture has a liquidus temperature of $125^{\circ} \mathrm{C}\left(257^{\circ} \mathrm{F}\right)$. A possible problem would be the release of $\mathrm{HCl}$ upon contact with water.

\section{Liquid Metals}

Several of the liquid metals possess the qualities necessary for transporting sensible heat:

1. low melting temperature,

2. thermal stability,

3. noncorrosiveness.

However, as evident from the following discussions, practically any liquid metal has at least one fundamental characteristic which essentially eliminates it from serious consideration.

Alkali metals, sodium, potassium, cesium. The alkali metals have low melting temperatures and specific heats as high as many of the molten salts. The corrosion characteristics of sodium, $\mathrm{NaK}$, and potassium are understood to a high degree and do not present a significant problem at $540^{\circ} \mathrm{C}\left(1000^{\circ} \mathrm{F}\right)$ or less. For example, a sodium test loop at the Oak Ridge National Laboratory has been operated for over $26,000 h .{ }^{25}$ The loop is constructed of stainless steel for the most part.

Over $100,000 \mathrm{~h}$ of test time were accumulated with potassium/stainless steel loops in conjunction with the Military Compact Reactor (MCR) program in the 1960s. Sodium and Inconel compatibility data were generated in the Aircraft Reactor Experiment and NaK/Hastelloy data in the SNAPprogram. ${ }^{26}$

In summary, the liquid metals would require materials of construction which are at least as exotic as those required for a nitrate/nitrite salt. The preliminary analysis in the previous section shows, however, that potassium is not as attractive from a transport capability standpoint which is mainly due . to potassium's relatively low specific heat, about $0.20 \mathrm{cal} / \mathrm{g}-{ }^{\circ} \mathrm{C}\left(0.20 \mathrm{Btu} / \mathrm{lb}-{ }^{\circ} \mathrm{F}\right)$. Adding to this the reactivity of the alkali metals with water and their flammability practically eliminates these materials from serious consideration. 
Bismuth and lead. These liquid metals are borderline in melting temperature for attractiveness as heat transport media. However, the heat capacity, $\sim 0.035 \mathrm{cal} / \mathrm{g}-{ }^{\circ} \mathrm{C}\left(0.035 \mathrm{Btu} / \mathrm{lb}-{ }^{\circ} \mathrm{F}\right)$, is an order of magnitude lower than the salts and alkali metals which essentially removes these materials from contention.

Mercury. Mercury could probably be eliminated from consideration based on its cost alone. Its inapplicability is magnified by a specific heat capacity of about $0.032 \mathrm{cal} / \mathrm{g}-{ }^{\circ} \mathrm{C}\left(0.032 \mathrm{Btu} / \mathrm{lb}-{ }^{\circ} \mathrm{F}\right)$, similar to the situation with lead.

\section{Organics and silicons}

As previously noted these materials are not applicable for energy transport at over $425^{\circ} \mathrm{C}\left(800^{\circ} \mathrm{F}\right)$. Their use is widespread and their applicability at temperatures only slightly below those of interest in this study warrants some further discussion.

The organic media are attractive due to their good compatibility with common materials, low vapor pressure, and high specific heats of $0.40-0.70 \mathrm{cal} / \mathrm{g}-{ }^{\circ} \mathrm{C}\left(0.40-0.70 \mathrm{Btu} / \mathrm{lb}-{ }^{\circ} \mathrm{F}\right)$ in the range of $100-425^{\circ} \mathrm{C}\left(212-800^{\circ} \mathrm{F}\right)$. These basic characteristics have resulted in oils being included in some economic studies of energy transport at moderate temperàtures. ${ }^{3,27}$

Under subcontract to ORNL, Hydroscience, Inc. conducted a study comparing hot water, hot oil, and steam for delivering heat in the $\left(250-350^{\circ} \mathrm{F}\right)$ temperature range. ${ }^{3}$ The delivered heat was used to generate hot water or steam and a wide variety of heat transport system sizes and distances were studied. The findings generally revealed that the oil was an economically inferior choice to both hot water and steam for distances up to $64 \mathrm{~km}$ (40 miles). As an energy storage medium, hot oil has been shown to be more competitive. ${ }^{27}$

The organics are all mildly toxic, flammable, and thermally unstable at high temperatures. A series of fire-resistant fluids, consisting of chlorinated biphenyls, was withdrawn from the market in 1972 due to concerns of environmental contamination. ${ }^{28}$ Deterioration of the organic fluids occurring through oxidation or cracking is proportional to temperature. Decomposition models accounting for radiolysis as well as pyrolysis have been documented in Ref. 7. Other stability studies cited in Ref. 28 demonstrated that exceeding the maximum recommended fluid temperature by only $10^{\circ} \mathrm{C}\left(50^{\circ} \mathrm{F}\right)$ could lead to a $10 \%$ material loss (due to volatile venting and carbon deposition) in a 2 to 4 week period of continuous operation. Regeneration of the fluids is possible, however, and the practice is apparently common.

Fouling - the formation of low thermal conductivity deposits on heat transfer surfaces-is one of the most significant problems associated with organic fluid systems. Although coking is actually a different phenomenon, it is often included in the category of fouling. Fouling is described as the deposition of film, inorganic and/or carbonaceous, on heat transfer surfaces and is caused by impurities in the fluid. Coking is characterized by massive carbonaceous deposits resulting from the precipitation and growth of decomposition products. Fouling is best controlled by maintaining high quality in the coolant chemistry while coking can be controlled by ensuring that hydraulic conditions in the heat exchanger are adequatc to avoid hot spots and.to carry away any deposits in solution.?

In summary, most of these problems-fouling, decomposition, flammability-will be characteristic of organics even if their temperature range is extended. Hence they may never be ideal fluids for high temperature energy transport. 


\section{THERMOCHEMICAL ENERGY TRANSPORT SYSTEMS}

This section provides a review of the development status of chemical heat pipes (CHP), in particular those which are currently under investigation. Current development activities and special problems are also discussed.

\section{EVA-ADAM}

The basic EVA-ADAM concept has been discussed in an earlier section. This CHP is, in the opinion of many, the only one likely to succeed and be implemented.

The range of temperatures required for the operation of this CHP can be examined in the equilibrium chart shown in Fig. $6 .{ }^{33}$ Temperatures in excess of $1000 \mathrm{~K}\left(1340^{\circ} \mathrm{F}\right)$ are viewed as necessary to drive the reaction to a degree sufficient for the system to be economical. The products of the reforming process are cooled before they proceed through the transport pipeline. Although the gaces are actually in a chemical nonequilibrium state, no reaction will take place in the pipeline until the mixture is heated and passed over a catalyst to start the methanation reaction.

Steam reforming of methane is a common industrial operation. Most of the ammonia produced in the United States, for example, is manufactured by obtaining hydrogen from the steam reforming of natural gas. A nickel catalyst is usually employed in the reaction and such is true in the current $\mathrm{CHP}$ conceptual studies and experiments.

Catalytic production of methane from carbon dioxide, carbon monoxide and hydrogen was first accomplished in 1902 and since then the literature on the subject, similar to the case with reforming, has

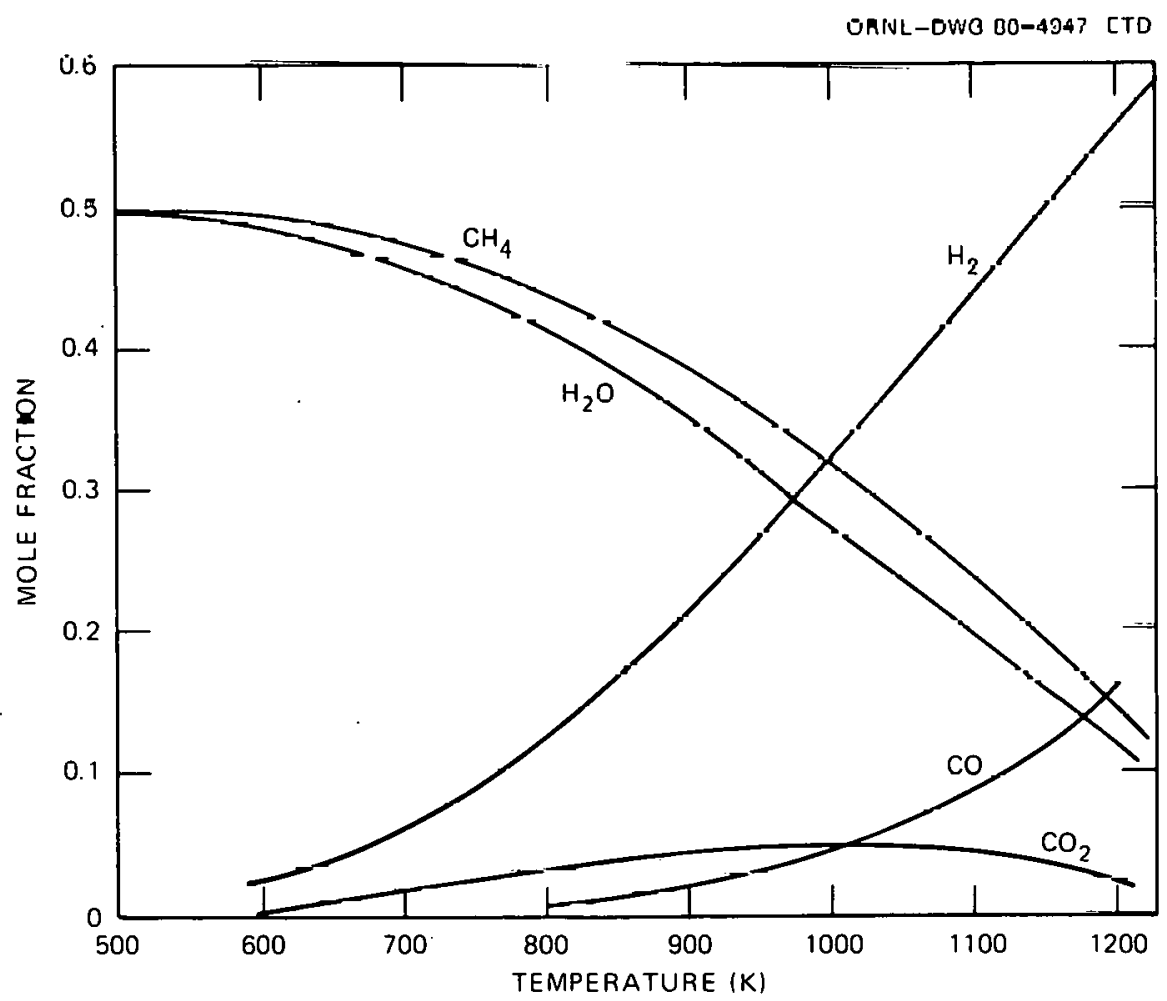

Fig. 6. Equilibrium compositions for the reaction $\mathrm{CH}_{4}+\mathrm{H}_{2} \mathrm{O}=\mathrm{CO}+3 \mathrm{H}_{2}$ at $40 \mathrm{ATM}\left(\mathrm{H}_{2} \mathrm{O} / \mathrm{CH}_{4}=1\right)$. Source: Unpublished work by Rocket Research Corporation for EPRI, 1977. 
become voluminous. Nickel catalysts have been found to be suitable for this reaction although iron catalysts have been used. Catalyst composition has a pronounced effect on carbon deposition which is a phenomenon to be avoided.

Catalysts generally lose their activity with time and would require occasional replacement in a CHP system resulting in higher costs and increased complexity of design to permit replacement. Trace quantities of sulfur and phosphates dramatically reduce catalyst life but might be of minimal concern in a closed loop system.

Recent and ongoing development activities on the EVA-ADAM concept includes systems economic studies and research on the interface between the reformer and nuclear and solar energy. The KFA Jülich in the Federal Republic of Germany has been leading in developing the nuclear interface specifically using the high-temperature pebble-bed reactor being developed in that country. This reactor is to be helium cooled. Tests with a helium heated reformer were started in 1972 in a small test unit consisting of one reformer tube and an electric heater as the energy source for the helium loop. ${ }^{8}$ During early tests a maximum helium temperature of about $1000^{\circ} \mathrm{C}$ was attainable which could heat the reformer gas to about $850^{\circ} \mathrm{C}\left(1562^{\circ} \mathrm{F}\right)$. The basic feasibility of a helium heated reformer was thus established. A larger pilot plant with 30 tubes has also been operated but was not a helium heated system. A 30 tube helium heated bundle is under construction, also electrically powered. Hence, tests with a nuclear powered reformer are still not to come in the immediate future.

Some of the significant findings resulting from the small scale tests are:

1. The steam reforming reaction is only limited by the heat transfer capabilities, and theoretical equilibria are fulfilled.

2. A maximum helium temperature of $950^{\circ} \mathrm{C}\left(1740^{\circ} \mathrm{F}\right)$ is adequate for the reaction giving methane conversion of 60 to $65 \%$.

The possibility of the permeation of hydrogen into the reactor coolant and the possible damage which might result is a problem which has not been completely resolved. A similar problem is the contamination of the reformer gas by tritium.

Early in 1979 a methanator system was coupled to the single tube reformer and the two were operated as an EVA-ADAM loop. The methanation reactor is also to be part of the 30-tube system which is now nearing completion. Steam generated by the methanator will be used at the site.

A joint GE-ERDA-KFA program to build and test a duplex tube reformer was formulated in 1977. ${ }^{29}$ This design is to reduce the hydrogen and tritium permeation rates and thereby eliminate the intermediàte heat exxchanger. A test unit was constructed by $\mathrm{GE}$ and delivered to the KFA for testing on the helium loop in 1979. Actual testing of the duplex tube reformer was performed in June-July of 1979. ${ }^{30}$ The test was to determine performance and not durability. A primary question was whether the small gap between the concentric tubes would degrade the heat transfer performance. It was determined that the thermal resistance of the gap was insignificant. The fabrication of such a tube is believed to be feasible, but there are questions of licensing and practicality which have not been resolved.

An EVA-ADAM system powered by solar energy is being studied and developed at the Solar Energy Laboratory of the University of Houston in Texas. ${ }^{31}$ Proponents of this system claim that a cost advantage may exist for use of solar power due to the disproportionate cost of nuclear power reactors with their stringent safety requirements. A preliminary economic study was reported in Ref. 32 in which major process parameters were evaluated with regard to efficiency and economics. Cost for delivered steam including the solar receiver and CHP system was estimated to be about $11.00 \$ / G \mathrm{~J}\left(11.00 \$ / 10^{6}\right.$ Btu) over a transport distance of $160 \mathrm{~km}$ ( 100 miles). This cost pertains to a $40 \mathrm{MWt}$ system which is sonewhat small by industry standards. 
Most other recent activities in EVA-ADAM development are of the nature of the economic study described above. A recent systems design and cost study by GE"I is perhaps the most comprehensive evaluation available. The economics of a $1000 \mathrm{MW}(\mathrm{th})$ system are identified over a wide range of distances. Pipe diameter was optimized and fairly detailed cost estimates for the reformer and methanator are contained in the report.

\section{Ammonia dissociation}

The ammonia cycle is under study primarily as a means of storing solar energy. Lenz of Colorado State University is among the most recent proponents although the reaction was also considered in a Rocket Research Corportion (RRC) study. ${ }^{10,33}$ As evident from Fig. 7, the reactions must occur at elevated pressure if the system is to be capable of delivering high temperature energy. The advantages of transporting the ammonia as a liquid could be significant. A previous study which examined ammonia as a hydrogen energy carrier concluded that transporting that form of energy was less expensive than moving natural gas. ${ }^{34}$

Some of the advantages of the ammonia $\mathrm{CHP}$ relative to other concepts are:

1. well-known large scale technology,

2. less corrosive than some other concepts,

3. good heat transfer,

4. reasonable catalyst cost likely.

Problems in this energy transport system would arise from having to transport a mixture of liquid $\mathrm{NH}_{3}$ and gaseous $\mathrm{H}_{2}$ although separate pipelines might be appropriate. The question of hydrogen embrittlement on the pipe material also exists. Such problems have probably little effect on chemical plants but are of major concern on a long pipeline system intended to last 30 years.

Another disadvantage may be a low chemical cycle energy efficiency, $\bar{R} \bar{R} C$ reported a storage cycle efficiency of less than $30 \%$. No cost estimates for a transport system have been derived. The toxicity and incapacitating effects of ammonia vapor on humans are cèrtainly negarive factors in considering this system for energy transport over long distances.

\section{Cyclohexane/ Benzene}

This concept has been proposed by GE as an alternative to the EVA-ADAM system. ${ }^{11,35}$ The benzene cycle requires a slightly lower driving temperature and therefore can be coupled to a wider variety of energy sources. It is seen as a more suitable cycle for the solar central receiver than EVA-ADAM. A major R\&D need identified by GE is catalyst development.* A cost estimate was performed for an energy transport system of $1000 \mathrm{MWt}$ size. A breakdown of the cost estimate is provided in Table 12. Cost of delivering the energy is presented graphically in Fig. 8. Note that the overall cycle efficiency was calculated to be in the neighborhood of $80 \%$. The efficiency of the RRC storage cycle was estimated at about $40 \%$, primarily since the latter was a stand-alone system not coupled to a power plant.

The toxicity of benzene and cyclohexane are well-known and is practically a sufficient reason to eliminate the concept from further consideration. If ever accepted as a potential candidate medium, the cost of safety related equipment would probably be excessive.

*RRC stated that a platinum or palladium catalyst might be required to minimize side reactions. 


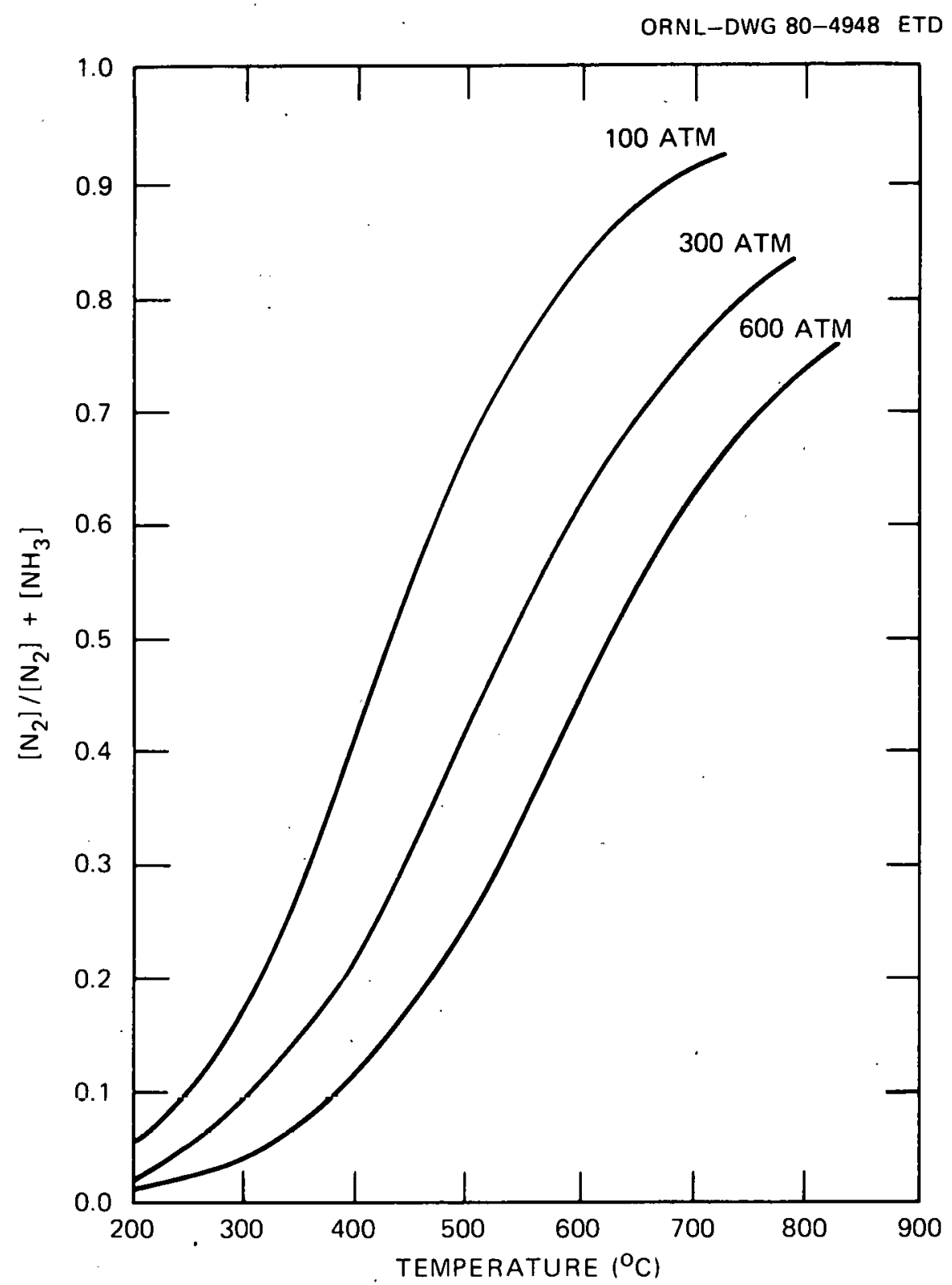

Fig. 7. Ammonia dissociation equilibria. Source: 1. G. Lenz, Proposal for Engineering Design Study of Conversion of Solar Energy to Chemical Energy Through Ammonia Dissociation, in proceedings of the Solar High Temperature Industrial Processes Workshop, Sept. 28-30, 1978, SERI/0637-4. 
Table 12. Summary of cost analysis for solar/LTCHP transmission of heat

\begin{tabular}{|c|c|c|c|}
\hline & $\begin{array}{c}\text { Dollars } \\
\left(10^{\circ}\right)\end{array}$ & $\begin{array}{c}\text { Percent } \\
\text { of } \\
\text { total }\end{array}$ & Dollars/GJ \\
\hline \multicolumn{4}{|l|}{ Capital costs } \\
\hline Dehydrogenation reactor and heat exchangers & 166.5 & 64.2 & \\
\hline Storage tanks & 2.0 & 0.8 & \\
\hline Transmission line & $54 . \dot{2}$ & 20.9 & \\
\hline Hydrogenation reactors & 36.5 & 14.1 & . \\
\hline Total & $\overline{259.2}$ & 100.0 & \\
\hline \multicolumn{4}{|l|}{ Yearly operating costs } \\
\hline Yearly capital cost, $20 \% /$ year & 51.8 & 59.5 & \\
\hline Power and losses ${ }^{a}$ & 12.2 & 14.0 & \\
\hline Undelivered heat at $132.8 \mathrm{MWt}$ & $\underline{23.0}$ & 26.5 & \\
\hline Total & 87.0 & 100.0 & \\
\hline Incremental LTCHP transportation cost ${ }^{b}$ & & & $3.0 \bar{y}$ \\
\hline Total cost of delivered heat & & & 9.09 \\
\hline
\end{tabular}

${ }^{a}$ Power and losses are calculated by $28.3 \mathrm{MW} \times 2.5=70.8 \mathrm{MWt}$

${ }^{b}$ At $2.81 \times 10^{7} \mathrm{GJ} /$ year.

Source: Ref. 35.

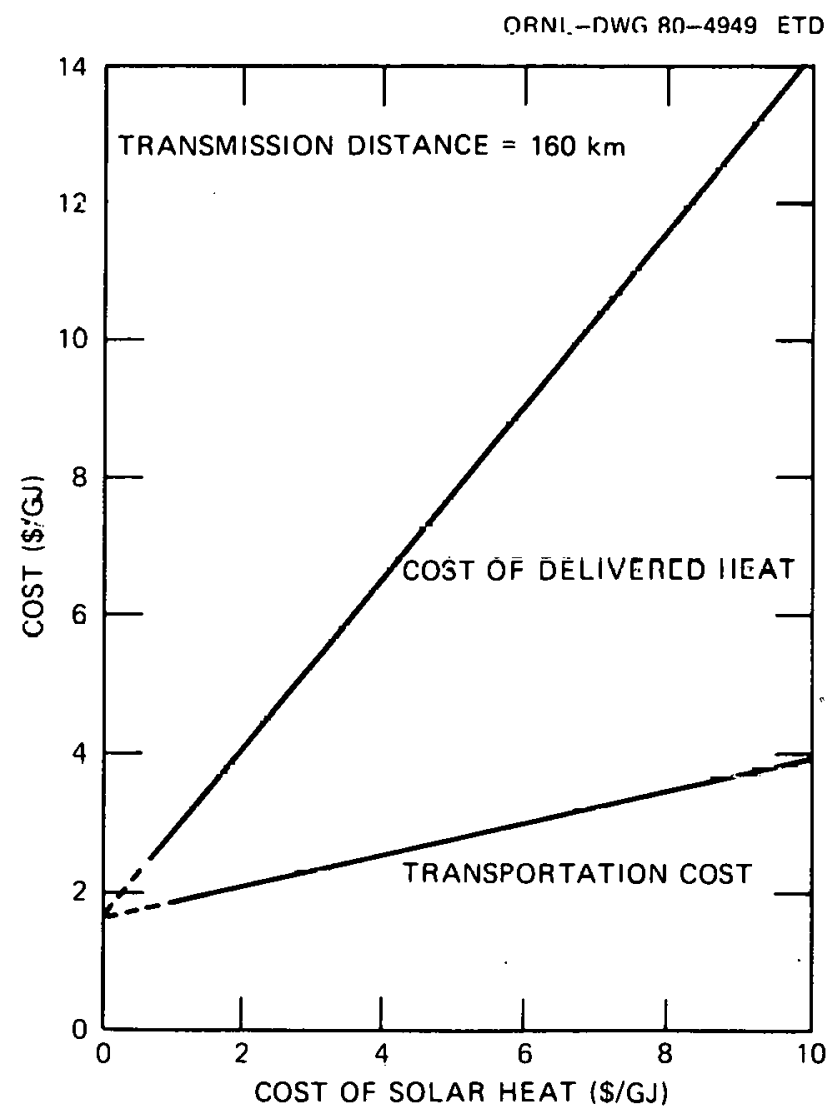

Fig. 8. Cost of LTCHP transportation and cost of delivered heat as a function of the cost of solar heat. Source: J. W. Flock et al., Process Steam End Use for Solar Energy Using Chemical Heat Pipes, in Proceedings of the Solar High tempearture Industrial Processes Workshop, Sept. 28-30, 1978, SERI 0637-4. 


\section{$\mathrm{SO}_{2} / \mathrm{SO}_{3}-$ Solchem}

The Naval Research Laboratory (NRL) and the RRC have been recently involved in research and development on the sulfur trioxide cycle. Development of suitable, long-life catalysts has been pursued by R RC through most of 1978-79.36 Their assessment of catalyst development needs are summarized in Table 13. The conclusions regarding current catalysts resulted from evaluation of numerous catalysts of different suppliers. No information was available on catalysts for $\mathrm{SO}_{3}$ dissociation since this is not a routine objective in sulfuric acid manufacturing.

Table 13. Current versus required $\mathrm{SO}_{\mathrm{x}}$ catalyst operating characteristics

\begin{tabular}{lll}
\hline & $\begin{array}{c}\text { Current } \\
\text { technology }\end{array}$ & $\begin{array}{l}\text { Required for } \\
\text { RCR TES }\end{array}$ \\
\hline Temperature, K $\left({ }^{\circ} \mathrm{F}\right)$ & $770(950)$ & $1,144(1,600)$ \\
Pressure, bar $(\mathrm{psia})$ & $1.01(14.7)$ & $15(220)$ \\
Feed gas composition & $\mathrm{Air} / \mathrm{SO}_{2}$ & $\mathrm{O}_{2} / \mathrm{SO}_{2}$ \\
Feed gas purity & $1 \mathrm{mpure}$ & Pure \\
Mode of operation & Open loop & Closed loop \\
Space velocity, $\mathrm{h}^{-1}$ & 2,000 & 10,000 \\
Catalyst life, years & $2-10$ & 30 (desirable) \\
\hline
\end{tabular}

By the end of 1978, 28 new catalysts had been prepared and tested. The tests were conducted at $827^{\circ} \mathrm{C}\left(1520^{\circ} \mathrm{F}\right)$ for a duration of about $300 \mathrm{~h}$.

Conceptual design studies and cost estimates have been reported by the NRL ${ }^{12}$ and Sandia Laboratories. ${ }^{37}$ The NRL study deals with energy storage and energy transport systems. The equilibrium curves presented in the study indicate the need for a higher temperature to drive the endothermic reaction than with the EVA-ADAM system. The study emphasizes a solar central receiver as the energy source for the chemical cycle.

The study of energy transport focused on the system depicted in Fig. 9 from the NRL study. The energy transport capacity was set at $100 \mathrm{MWt}$. The system parameters are shown in Table 14. No cost

SOLAR ENERGY SITE

ORNL-DWG 80-1860 ETD

INDUSTRIAL PARK

\begin{tabular}{|c|c|c|}
\hline \multicolumn{3}{|c|}{ PIPELINES } \\
\hline THERMOCOUPLE RECEIVERS & & - $\mathrm{SO}_{3}$ SYNTHESIZERS \\
\hline COMPRESSORS & $\mathrm{O}_{2}(\mathrm{~g}) \longrightarrow$ & - $\mathrm{SO}_{2}$ VAPORIZERS \\
\hline CONDENSERS & $\mathrm{SO}_{2}(\mathrm{l}) \longrightarrow$ & - CONDENSERS \\
\hline CHEMICAL STORAGE TANKS & & - PUMPS \\
\hline PUMPS & $\longleftarrow \mathrm{SO}_{3}(\mathrm{Q})$ & \\
\hline
\end{tabular}

Fig. 9. Configuration for $\mathrm{SO}_{2} / \mathrm{SO}_{3}$ energy transport system. Source: T. A. Chubb, Energy Collection and Transport U/sing the $\mathrm{SO}_{3} / \mathrm{SO}_{2} / \mathrm{O}_{2}$ Thermochemical Cycle; $\mathrm{PF}_{3} \mathrm{H}_{2}$ as a Possible Thermochemical Fluid, in Proceedings of the Solar High Temperature Industrial Processes Workshop Sept. 28-30, 1978, SERI/0637-4 
Table 14. $100 \mathrm{MWt}, 160 \mathrm{~km}$ energy transport system using $20-\mathrm{cm}$ lines

\begin{tabular}{|c|c|c|c|}
\hline & \multicolumn{3}{|c|}{ Items } \\
\hline & $\mathrm{O}_{2}$ & $\mathrm{SO}_{2}$ & $\mathrm{SO}_{3}$ \\
\hline Direction & $A \rightarrow B$ & $A \rightarrow B$ & $B \rightarrow A$ \\
\hline Phase/pressure & 8.28 M Pa gas & Liquid & Liquid \\
\hline Line temperature, ${ }^{\circ} \mathrm{C}$ & 20 & 20 & 40 \\
\hline Pumping power, $\mathrm{MW}$ & 1.2 & 0.6 & 0.8 \\
\hline Air conditioning provided, tons & & 6450 & \\
\hline Flow rates, $10^{3} \mathrm{~kg} / \mathrm{d}^{-1}$ & 1408 & 5640 & 7050 \\
\hline Inventory, $\mathrm{kg} \approx 10^{3}$ & 568 & 7500 & 9572 \\
\hline Line energy storage, $d$ & 0.4 & 1.3 & 1.4 \\
\hline
\end{tabular}

estimates were reported. The unique problems associated with liquid $\mathrm{SO}_{3}$ make its transport feasibility doubtful. These problems are associated with multiple solid phases of $\mathrm{SO}_{3}$ which can be formed if the liquid conditions are not maintained in a fairly narrow range. Chubb of the NRL has given a detailed explanation of the behavior of liquid and solid $\mathrm{SO}_{3}$.

Mild steel is suitable for containing $\mathrm{SO}_{3}$ at low temperatures provided there is no water present. ${ }^{14}$ Teflon may be suitable as a gasketing material.12

The Sandia study dealt mainly with the importance of chemical cycle efficiency as related to the economics of a storage system. The reported efficiency of storing chemical energy via the $\mathrm{SO}_{2} / \mathrm{SO}_{3}$ cycle was about $41 \%$ which does not include losses in recovering thermal energy from the stored chemical energy. A significant amount of the loss occurs where heat must be exchanged by streams with mismatched temperatures resulting in high irreversibilities. Efficiencies for the energy storage and recovery cycle were also reported as less than $50 \%$ by $\mathrm{RRC}$.

\section{Open-loop CHP}

The Institute of Gas Technology (IGT) performed a study on an open loop EVA-ADAM system. ${ }^{9}$ In this concept the natural gas formed during methanation is burned instead of being returned to a reformer. A simple flow diagram is shown in Fig. 10.

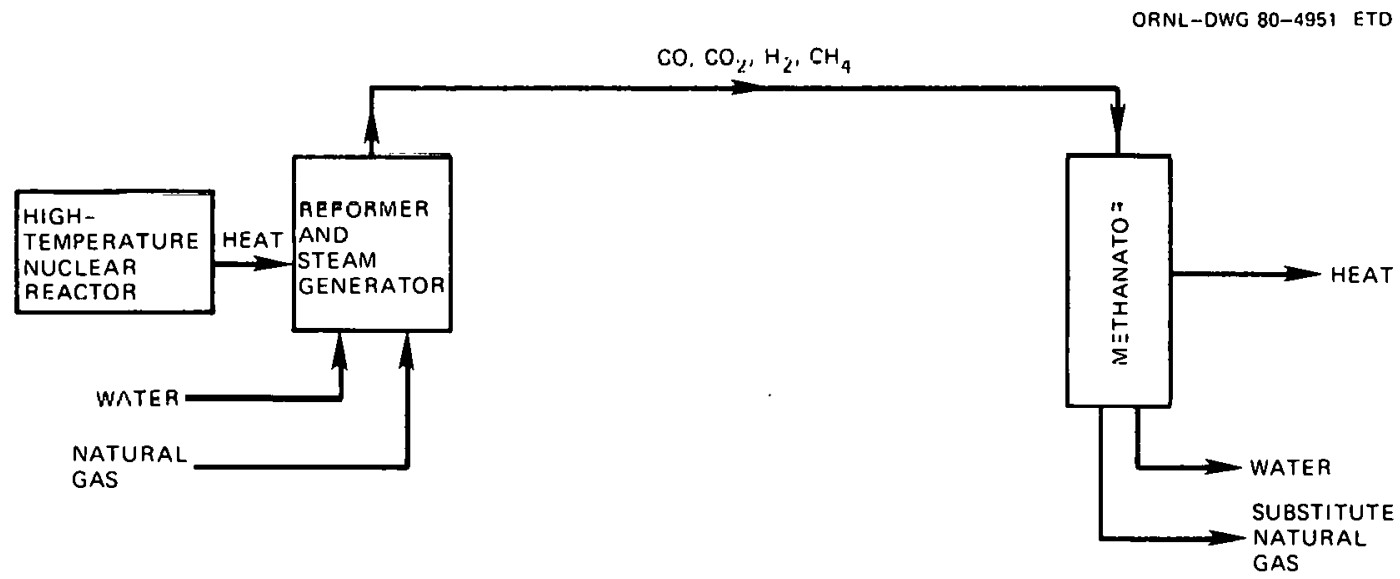

Fig. 10. Conceptualization of open-loop chemical energy pipeline. Source: Transmission of Energy by Open-Loop Chemical Energy Pipelines, Project 8990 Final Report, Institute of Gas Technology (June 1978). 
Since one mole of $\mathrm{CH}_{4}$ if completely reformed will result in a mole of $\mathrm{CO}$ and 3 moles of $\mathrm{H}_{2}$ the volume flow of gas would increase by a factor of four over piping natural gas alone. The additional energy transported by the chemical reaction (reforming and methanating) is only about 10 to $15 \%$ of the heating value of methane at best.

This fact creates serious doubts as to the economic feasibility of the concept. The IGT study confirmed that this base system did not appear to be economically competitive. Integration of a coal gasifier with the concept was found to be more attractive than using nuclear energy as the prime heat source. Hydrogen embrittlement is also a potential problem with this system.

\section{Other CHP cycles}

Chubb has discussed a possible chemical cycle using $\mathrm{PF}_{3} \mathrm{H}_{2}$, a stable inorganic vapor which is believed to dissociate into $\mathrm{PF}_{3}$ and $\mathrm{H}_{2}$ plus some $\mathrm{PF}_{3} \mathrm{H}$ and $\mathrm{HF}$. The highly corrosive nature of $\mathrm{HF}$ makes this system of little interest although dissociation temperatures are in the desirable 400 to $550^{\circ} \mathrm{C}$ $\left(750\right.$ to $\left.1020^{\circ} \mathrm{F}\right)$ range. ${ }^{12}$

An ethylene/ethane system has the attractive feature of a transportable liquid phase. However, a catalyst for dehydrogenating ethane is not available and there is a high possibility of carbon deposition during the reaction.

A cycle based on decomposing ammonium hydrogen sulfate has been studied at the University of Houston. ${ }^{38,39}$ The reaction is

$$
\mathrm{NH}_{4} \mathrm{SO}_{4(8)}=\mathrm{NH}_{3(\mathrm{~g})}+\mathrm{SO}_{3(\mathrm{~g})}
$$

$\mathrm{The} \mathrm{SO}_{3}$ and ammonia must be separated after the reaction for storage or transport since the reaction proceeds without catalysts. This is a disadvantage for transport since multiple pipes might be necessary but it appears that all constituents could be liquified. The liquid $\mathrm{SO}_{3}$ problems in transport systems must be noted, however. Separation techniques are available ${ }^{38}$ and would reportedly not be a serious problem.

It is apparent that, although much work has been done, an ideal CHP has still not been discovered. Possibly basic research is more appropriate for the CHP concept rather than development and design efforts on marginally attractive systems. 


\section{PRELIMINARY ECONOMIC ASSESSMENT OF ENERGY TRANSPORT CONCEPTS}

\section{Basic Parameters and Level of Detail}

An industrial plant which uses about $454,500 \mathrm{~kg} / \mathrm{h}(1,000,000 \mathrm{lb} / \mathrm{h})$ of steam consumes energy at the rate of about $350 \mathrm{MWt}\left(1.2 \times 10^{9} \mathrm{Btu} / \mathrm{h}\right)$. This plant size is about average for industries in the United States and was therefore chosen for this study. Common industrial high temperature steam conditionins of $4.5 \mathrm{MPa}(650 \mathrm{psia})$ and $400^{\circ} \mathrm{C}\left(750^{\circ} \mathrm{F}\right)$ were selected for the economic study. Conceptual pipeline designs were performed for distances of $24 \mathrm{~km}$ ( 15 miles), $80 \mathrm{~km}$ ( 50 miles), and $160 \mathrm{~km}$ (100 miles). By covering the long range of distances the economics of single long pipelines and shorter branch lines can be investigated. Conceptual arrangements for the location of power plants to industrial sites as shown in Fig. 11 reveal the need for examining a broad range of energy lrauspuit distances. Maximum driving temperatures were on the order of $593^{\circ} \mathrm{C}\left(1100^{\circ} \mathrm{F}\right)$ but were not rigidly set. The individual transport concepts were assumed to be supplied with energy at their required source temperature.

A target cost of process steam from a well-known alternate technology was selected to place the cost of transported energy in perspective. Coal-fired industrial boilers were chosen for setting this target cost.

The primary concern in this economic evaluation is the cost of the pipeline used to transport the fluids. Two reasons for emphasis on the pipeline are:

1. the pipeline usually accounts for a large fraction of the transport system cost and

2. costs for pipelines are generally available and involve less uncertainty than reformers, methanators, heat exchangers, etc.

Costs of pipes carrying Hitec and steam were derived for pipes ranging in size from $61 \mathrm{~cm}(24 \mathrm{in}$.) to $178 \mathrm{~cm}$ ( $7.0 \mathrm{in}$.). The CHP system was assigned a delivery pipe size of $76 \mathrm{~cm}$ ( $30 \mathrm{in}$.) and a return pipe size of $61 \mathrm{~cm}(24 \mathrm{in}$.).

Carbon steel pipe was assumed to be suitable for the CHP. Steam pipe was assumed to be a chromium alloy steel, and a stainless steel was used fü Hitec. The wall thickness was adjüsted for pressure requirements. Costs for the pipe materials are given in Appendix A. Estimates for the Hitec pipeline were also made for croloy steel and carbon steel using guidelines in cost estimating handbooks $\mathrm{s}^{40}$ for the effect of material on pipe cost.

Flnw rates of steam and Hitec were based on generating $454,500 \mathrm{~kg} / \mathrm{h}\left(10^{6} \mathrm{lb} / \mathrm{h}\right)$ of steam at the previously noted conditions. Feedwater was assumed to be supplied at $16^{\circ} \mathrm{C}\left(60^{\circ} \mathrm{F}\right)$. The return temperature for Hitec was greater than $260^{\circ} \mathrm{C}\left(500^{\circ} \mathrm{F}\right)$ to avoid freezing or extremely high viscosity. Steam condensate was assumed to return to the heat source at a maximum temperature of $\left(38^{\circ} \mathrm{C}\right) 100^{\circ} \mathrm{F}$ in a $36 \mathrm{~cm}$ ( $14 \mathrm{in}$.) pipe. Flow rates and flow constituents for the CHP were obtained from the GE study. Although the GE study is of considerable detail, the performance of some components was assumed to be ideal. For example, the condensers are assumed to be ideal since no water is identified in the flow constituents.

Flow rates are provided in Appendix B. Vertical turbine pumps were assumed satisfactory for Hitec. Costs and performance were obtained by comparison to liquid metal pumps and coal slurry pumps. The pumps were assumed to be electrically driven and the cost of the electric distribution system was included.

Compressor stations for the gas pipelines were conventional but electrically driven. Cost of the pumps and compressors are provided in Appendix A. Other ground rules for the cost estimates are also included in Appendix A. 

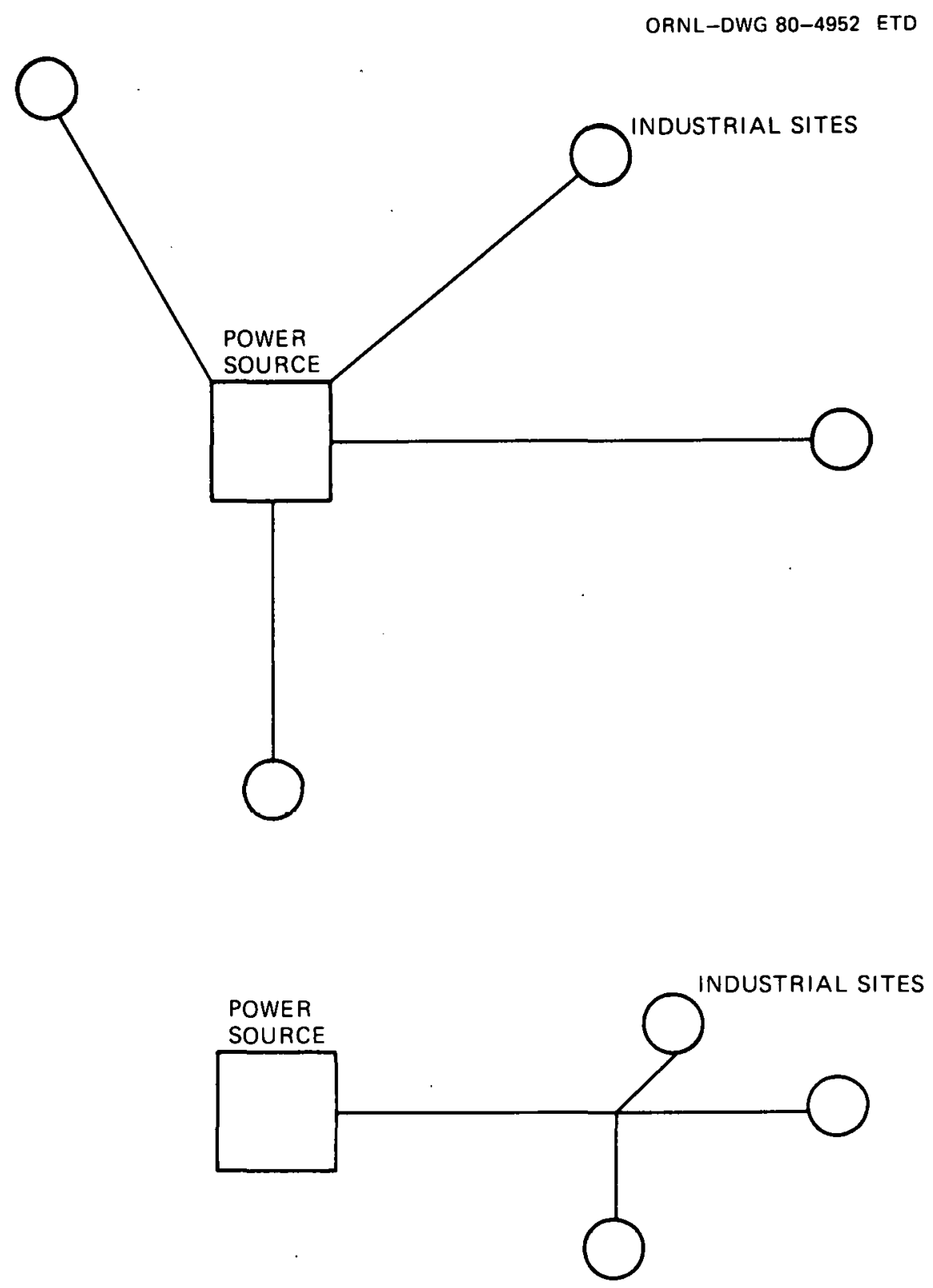

Fig. 11. Possible siting arrangements requiring different energy transport modes.

\section{Interest and contingencies}

The factors identified in Table 15 were obtained from cost estimating handbooks. ${ }^{40,41}$ The factors were applied to the basic materials and labor cost which includes a $25 \%$ increase for miscellaneous equipment.

A maintenance cost of $5 \%$ of the annualized capital cost was assigned to the EVA-ADAM system since it is the most complex system with catalysts requiring occasional replacement. For this 
Table 15. Economic evaluation factors

\begin{tabular}{lc}
\hline & Percent \\
\hline Contingency & 30 \\
Indirects $^{a}$ & 30 \\
Interest during construction & \\
$24 \mathrm{~km}(15$ mile) 2 year & 8 \\
$80 \mathrm{~km}$ (50 mile) 4 year & 18 \\
$160 \mathrm{~km}$ (100 mile) 7 year & 35 \\
Annual fixed charge rate & 18 \\
Capacity factor & 80 \\
\hline
\end{tabular}

${ }^{a}$ Includes engineering, construction overhead, insurance, etc.

preliminary evaluation no maintenance costs were assigned to the other systems although it is likely that the HTS would require inventory makeup. Poiwèr for pumpl ng motors was assumed to cost $3.5 \mathrm{c} / \mathrm{kWh}$.

A matrix showing cost estimates for the systems which were evaluated is shown in Table 16. The economic pipe diameter for the Hitec system was estimated to be slightly less than the smallest size shown. Since the steam system has no pumps, the pressure drop and heat loss limit the usable pipe diameters.

Table 16. Capital costs of pipeline systems $\left(\$ \times 10^{6}\right)$

\begin{tabular}{lcccc}
\hline & & \multicolumn{3}{c}{ Cost pcr distance } \\
\cline { 3 - 5 } & $\begin{array}{c}\text { Pipe diameter } \\
{[\mathrm{cm}(\text { in. })]}\end{array}$ & $\begin{array}{c}24 \mathrm{~km} \\
(15 \mathrm{miles})\end{array}$ & $\begin{array}{c}80 \mathrm{~km} \\
(50 \mathrm{miles})\end{array}$ & $\begin{array}{c}160 \mathrm{~km} \\
(100 \mathrm{miles})\end{array}$ \\
\hline Hitec: $^{a}$ & $61(24)$ & 67 & 217 & 460 \\
& $76(30)$ & 105 & 277 & 555 \\
& $102(40)$ & 134 & 386 & 773 \\
Steam & $127(50)$ & 149 & 500 & 1000 \\
& $76(30)$ & 83 & & 1071 \\
EVA-ADAM & $127(50)$ & 164 & 531 & \\
& $178(70)$ & 189 & 628 & 356 \\
\hline
\end{tabular}

anose not include sonst nf inventnry.

A breakdown of the contributors to the capital cost is helpful in identifying areas which should receive attention in efforts to reduce the system cost. A typical breakdown is shown in Table 17 for the respective systems.

Table 17. Break down of capital cost for typical 80 km (50 mile) system

\begin{tabular}{lccccc}
\hline & $\begin{array}{c}\text { Pipe } \\
(\%)\end{array}$ & $\begin{array}{c}\text { Insulation } \\
(\%)\end{array}$ & $\begin{array}{c}\text { Pump } \\
\text { equipment } \\
(5 \%)\end{array}$ & $\begin{array}{c}\text { Labor } \\
(\%)\end{array}$ & $\begin{array}{c}\text { Inventory } \\
(\%)\end{array}$ \\
\hline Hitec $^{b}$ & 45 & 6 & 8 & 27 & 14 \\
Steam $_{\text {EVA-ADAM }}$ & 61 & 9 & 7 & 30 & \\
\hline
\end{tabular}

${ }^{a}$ Excludes $25 \%$ miscellaneous charge.

${ }^{b}$ Stainless steel pipe. 


\section{Comparison of annual costs}

Figure 12 shows the annualized costs of the least expensive systems for the respective energy transport media. Obviously there is a substantial savings in the Hitec system if carbon steel could be substituted for the stainless steel delivery pipe. Further reduction in cost would result from use of a less expensive salt. Basic cost data are shown in Table 18.

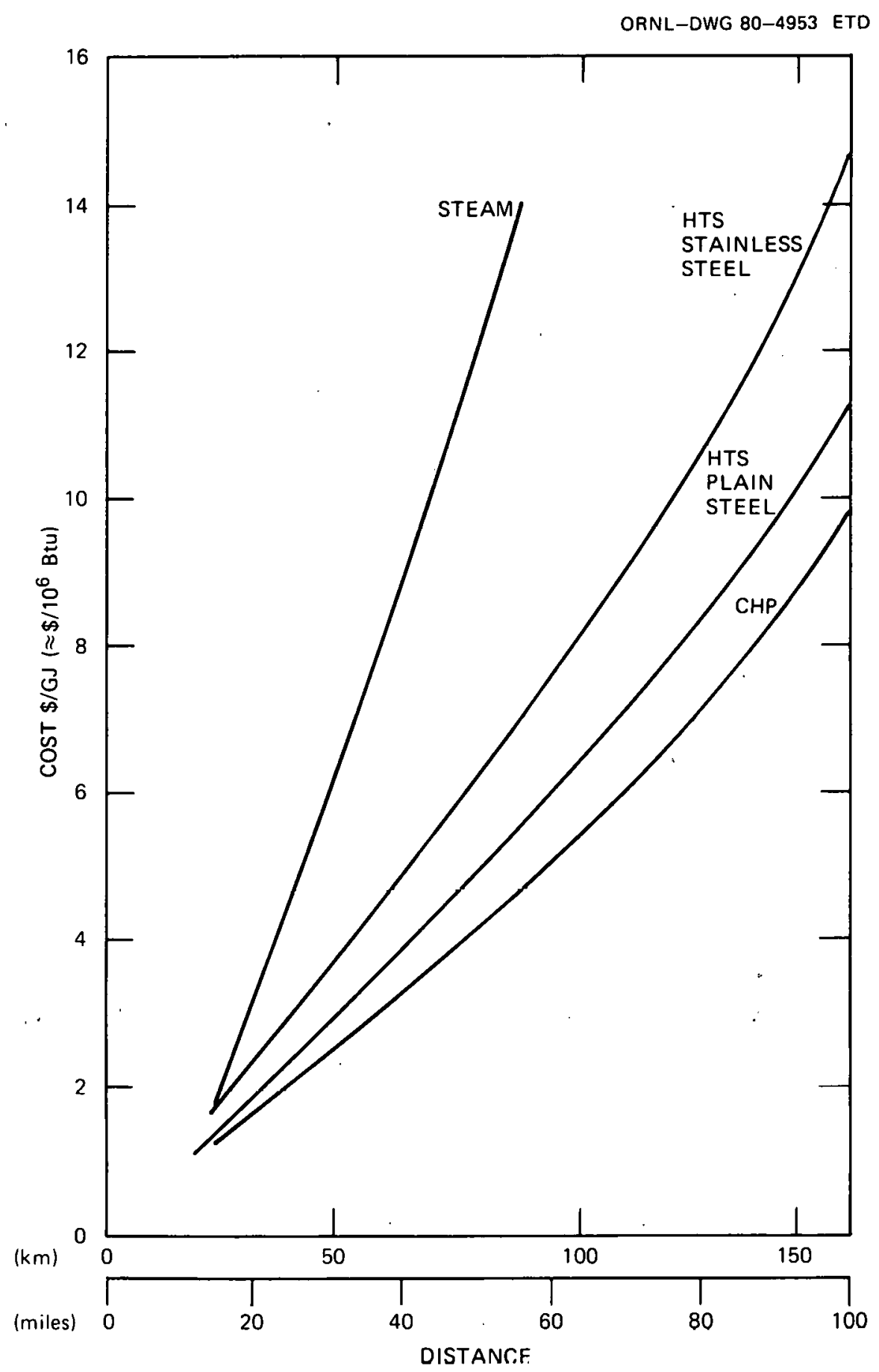

Fig. 12. Annualized cost of energy transport system. 
Table 18. Basic data for annual cost

\begin{tabular}{|c|c|c|c|c|c|c|c|}
\hline Medium & $\begin{array}{c}\text { Pipe } \\
\text { diameter } \\
{[\mathrm{cm}(\mathrm{in} .)]}\end{array}$ & $\begin{array}{c}\text { Distance } \\
{[\mathrm{km} \text { (mile) }]}\end{array}$ & $\begin{array}{c}\text { Capital } \\
\text { cost } \\
\left(10^{6} \$\right)\end{array}$ & $\begin{array}{l}\text { Annual } \\
\text { capital } \\
\left(10^{6} \$\right)\end{array}$ & $\begin{array}{c}\text { Pump PWR } \\
\left(10^{6} \mathrm{~S}\right)\end{array}$ & $\begin{array}{l}O \& M \\
\left(10^{6} \$\right)\end{array}$ & $\begin{array}{l}\text { Annual cost } \\
{[\$ / G J} \\
\left.\left(\$ / 10^{6} \mathrm{Btu}\right)\right]\end{array}$ \\
\hline \multirow[t]{13}{*}{ Hitec $^{\circ}$} & $61(24)$ & $24(15)$ & 78 & 15.2 & 1.50 & 0 & 1.76 \\
\hline & & $80(50)$ & 249 & 52.9 & 5.0 & & 6.13 \\
\hline & & $160(100)$ & 533 & 129.5 & 10.0 & & 14.76 \\
\hline & $76(30)$ & $24(15)$ & 122 & 23.7 & 0.32 & & 2.54 \\
\hline & & $80(50)$ & 334 & 170.9 & 1.06 & & 7.62 \\
\hline & & $160(100)$ & 669 & 162.6 & 2.12 & & 17.40 \\
\hline & $102(40)$ & 24 (15) & 164 & 31.9 & 0.04 & & 3.38 \\
\hline & & $80(50)$ & 487 & 103.4 & 0.12 & & 10.96 \\
\hline & & $160(100)$ & 975 & 236.97 & 0.24 & & 25.10 \\
\hline & $127(50)$ & $24(15)$ & 196 & 38.1 & 0.02 & & 4.03 \\
\hline & & $80(50)$ & 658 & 139.8 & 0.06 & & 14.80 \\
\hline & & $160(100)$ & 1317 & 320.0 & 0.12 & & 33.90 \\
\hline & $61(24)$ & $80(50)$ & $192^{b}$ & 40.8 & 5.0 & & 4.85 \\
\hline \multirow[t]{6}{*}{ Steam } & $76(30)$ & 24 (15) & 83 & 16.14 & 0 & 0 & 1.71 \\
\hline & $127(50)$ & $24(15$ & 164 & 31.90 & & & 3.37 \\
\hline & & $80(50)$ & 531 & 112.80 & & & 11.93 \\
\hline & & $160(100)$ & 1071 & 260.30 & & & 27.5 \\
\hline & $178(70)$ & 24 (15) & 189 & 36.74 & & & 3.89 \\
\hline & & $80(50)$ & 628 & 133.40 & & & 24.01 \\
\hline \multirow[t]{3}{*}{ EVA-ADAM } & $76 / 61(30 / 24)$ & $24(15)$ & 53 & 10.3 & 0.9 & 0.5 & 1.24 \\
\hline & & $80(50)$ & 162 & 34.4 & 2.9 & 1.5 & 4.11 \\
\hline & & $160(100)$ & 356 & 86.5 & 5.8 & 3.2 & 10.11 \\
\hline
\end{tabular}

${ }^{a}$ Hitec systems include inventory at $26 \mathrm{c} / \mathrm{kg}$ stainless steel pipe.

${ }^{b}$ Carbon steel pipe.

\section{Effect of heat exchanger and chemical reactor costs}

A detailed cost estimate of the steam generaturs and chemical reactors for the heat transport systems is not included in the scope of this study. However, some rough estimates were generated since these costs are of special significance in the CHP system.

Costs of the HTS steam generator were derived by assigning a cost of $1000 \$ / \mathrm{m}^{2}\left(y^{3} \mathrm{\$} / \mathrm{tt}^{2}\right)$ to a calculated heat transfer surface area.

The CHP reformer and methanator plant costs wèré taken from an earlieı GE sludy" aind escalated at $8 \%$ per year to 1979 costs. A somewhat arbitrary installation cost factor was used by GE to arrive at these costs. No additional contingencies were added. The same indirects were applicd to the GE costs to be consistent with the pipeline costs generated in this study. The resulting capital costs are summarized in Table 19.

\begin{tabular}{lc}
\multicolumn{2}{|c}{$\begin{array}{c}\text { Table 19. Cost of heat } \\
\text { exchange equipment }\end{array}$} \\
\hline & $\begin{array}{c}\text { Cost } \\
\left(\$ \times 10^{6}\right)\end{array}$ \\
\hline HTS heat exchangers & 8.0 \\
CHP reformer & $54.6^{\circ}$ \\
CHP methanator & $18.9^{b}$ \\
\hline
\end{tabular}

${ }^{a}$ Reported by GE as $66 \$ / \mathrm{kWt}$.

${ }^{b}$ Reported by GE as $29 \$ / \mathrm{kWt}$. 
To attain the efficiencies reported by GE which were used in this study it is essential that the CHP be closely coupled to a steam electric power plant. The $\mathrm{CHP}$ must have high pressure extraction steam from the turbine and requires a demand for lower pressure steam which cannot be used in the chemical reactor. The cost associated with that part of the power plant which serves the CHP reactor is included in these costs derived by GE. It is not clear whether costs associated with the additional piping were included.

\section{Cost of prime heat and efficiency}

The cost of prime heat has been treated parametrically in this study with values of 2.50 to $3.50 \mathrm{~S} / \mathrm{GJ}$ being considered as typical.

The efficiency of the heat transport pipelines is defined as

$$
\gamma=\frac{\text { Steam Energy Delivered }}{\text { Net Prime Heat Input }}
$$

Using this definition the efficiency of the HTS system is about $80 \%$ and that reported for the CHP system by $\mathrm{GE}$ was $89 \%$. The GE value was used in this study in generating the data for total cost of steam discussed in this section.

The efficiency of the energy transport systems is very important in that prime heat costs and possibly pipeline costs would increase with a drop in efficiency. To obtain high efficiency with the CHP it is advisable to exchange heat in discrete temperature bands with a power plant since a significant quantity of energy cannot be used regeneratively in a stand-alone CHP system. The GE HTR Multiplex system is a concept being studied which is intended to avoid this problem and maintain a high overall efficiency. ${ }^{42}$

\section{Total cost of steam using transported energy}

By combining the costs discussed in previous sections a total cost of steam can be generated. The respective systems are seen in Fig. 13 to have ranges of distance where each is most suitable. The trends are similar to that noted by General Atomic in an earlier study.

Note the extreme importance of the pipeline material in the HTS system. If carbon steel could he made suitable, then the HTS system would be the most attractive at practically any distance. Carbon steel has been found to be suitable as long as temperatures are held below $455^{\circ} \mathrm{C}\left(850^{\circ} \mathrm{F}\right)$. Even at this lower maximum temperature, it is possible to generate high pressure saturated steam or slightly superheated high pressure steam. A lower temperature HTS system would necessitate a larger flow rate and larger pipe size for a particular thermal output, however, which would decrease the cost advantage offered by plain steel pipc.

\section{Comparison to Other Steam Supply Method}

Industry is heavily dependent on oil and gas to generate steam. The rising cost of these fuels plus governmental pressure will continually make coal more attractive for this purpose. The cost of steam generated from small coal-fired boilers was therefore used as target for the cost of steam via transported energy.

The cost of steam from coal-fircd boilers of various sizes is shown in Fig. 14. These costs were derived using industrial financing and coal at $36 \$ / \mathrm{Mg}$ ( $33 \$ /$ ton). 


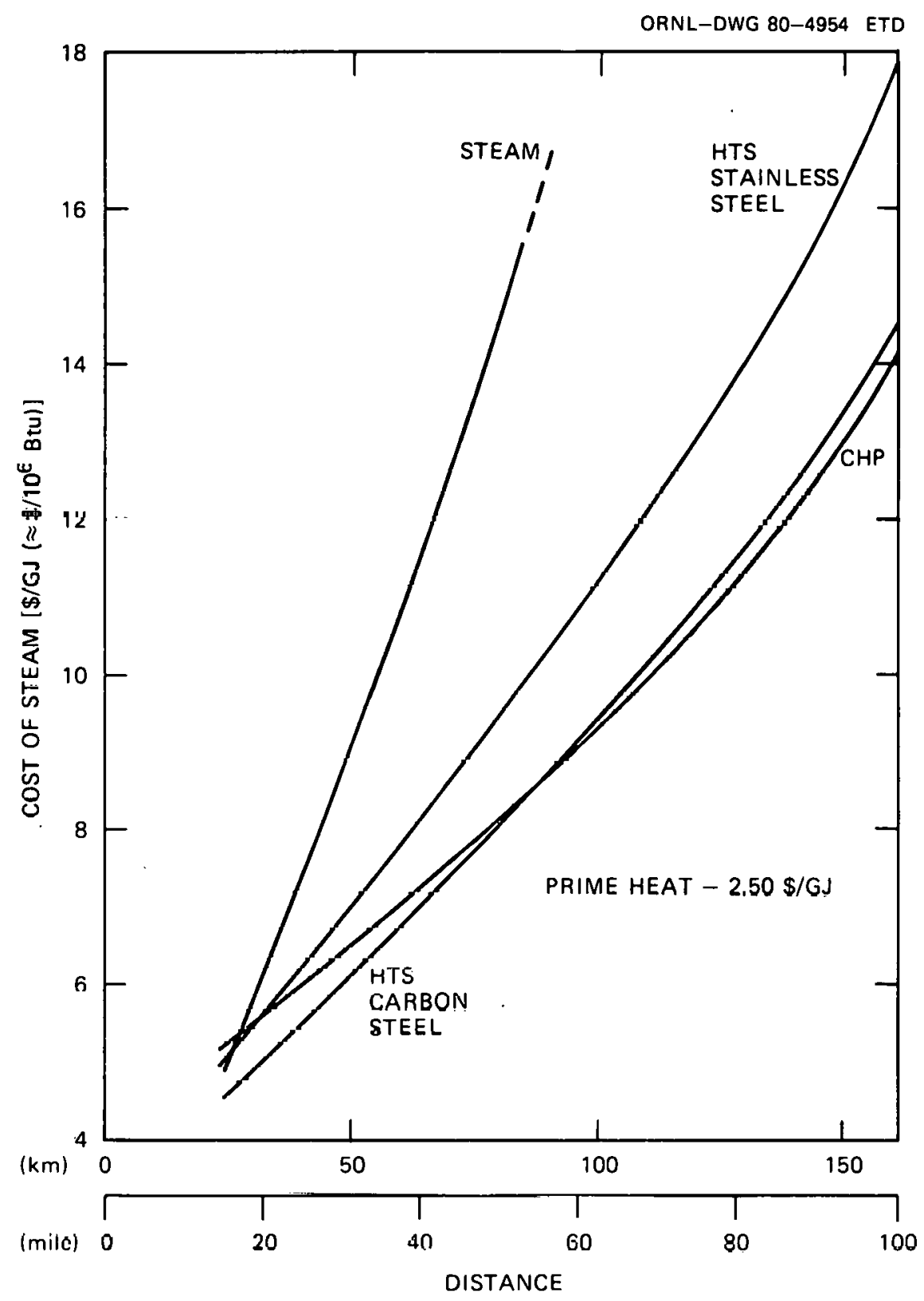

Fig. 13. Cost of steam generated hy transported energy.

By referring to the cost of steam via energy transport it is evident that no transport system is attractive where distances greater than about $40 \mathrm{~km}$ ( 25 miles) are involved and when a site has the option of using a coal-fired boiler generating $4.5 \times 10^{5} \mathrm{~kg} / \mathrm{h}\left(10^{6} \mathrm{lb} / \mathrm{h}\right)$ of steam. The distance can be greater, however, if energy is delivered to a central location in very close proximity to several smaller users. A cost of prime heat other than that noted in Fig. 12 would, of course, alter these conclusions.

\section{Comparison to prior work}

The EVA-ADAM CHP has been studied by ORNL previously as part of an assessment of very high-temperature reactor applications. ${ }^{43}$ This analysis was reasonably detailed and included the costs 


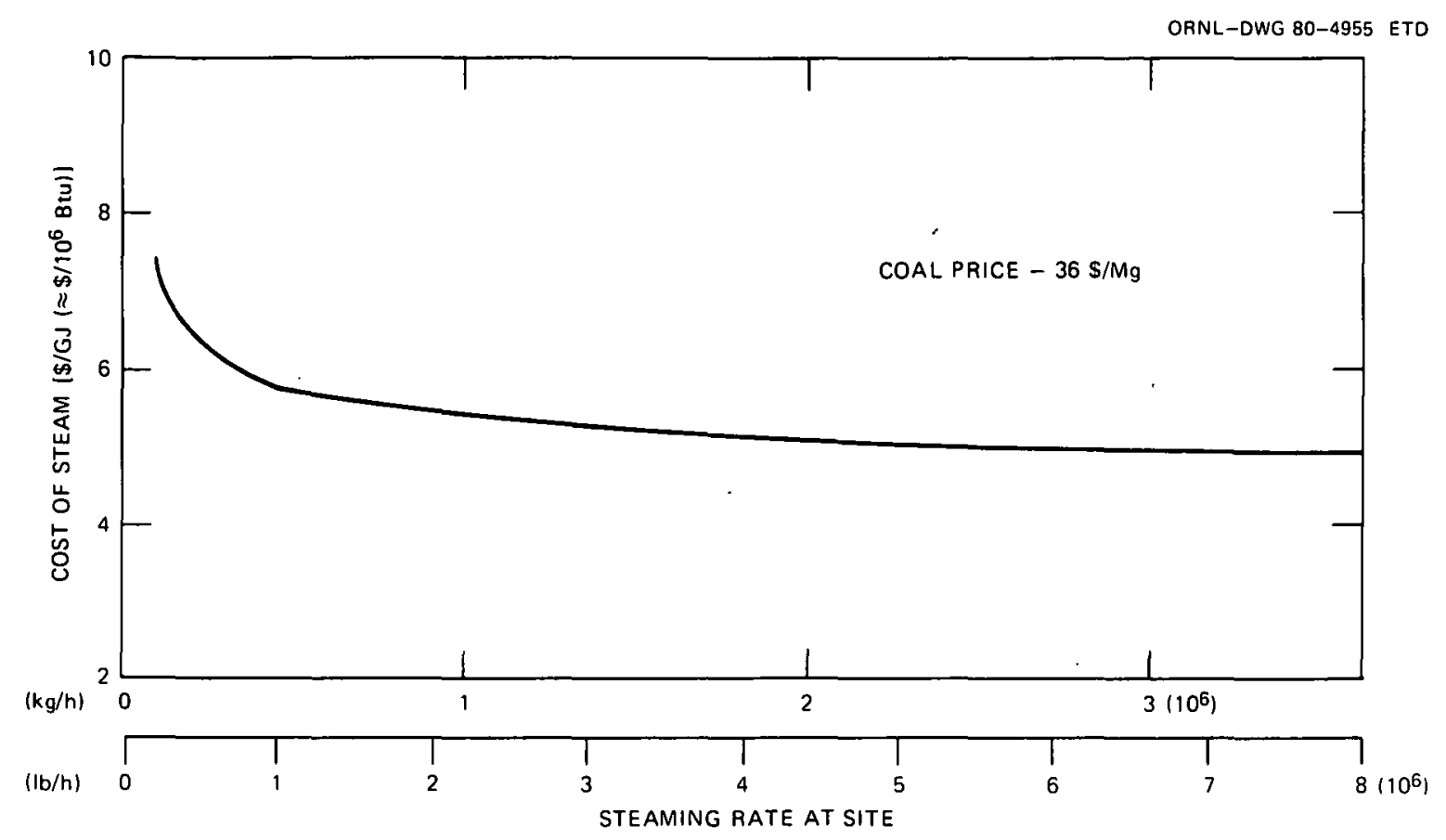

Fig. 14. Effect of boiler installation size on cost of steam from coal firing.

associated with the heat exchangers used to couple the $\mathrm{CHP}$ reformer to the power plant. Costs for the reformer and heat exchangers are comparable to those used in the present study. Methanator costs in the previous study are somewhat lower than the estimates from the GE study which have been used here. The pipeline cost estimates are also comparable if one eliminates the $25 \%$ miscellaneous cost added to all pipeline systems in the present study.

General Atomic (GA) has published work which examines the economics of transporting energy via the same media as in the present study. ${ }^{44}$ There are several notable differences itemized here:

1. Size-the GA transport system was $2000 \mathrm{MW}$.

2. Electricity credit-GA allowed credit for the power produced by the HTGR.

3. The GA fixed charge rate was $10 \%$.

4. GA used a $90 \%$ capacity factor.

The economy of scale is very prominent in energy transport systems in that the fluid carrying capacity is proportional to the pipe diameter squared whereas the cost of the pipe increases fairly linearly with pipe diameter. After taking this difference into account along with inflation and the different capacity factor, the costs of the GA study can be seen as in reasonable agreement with the values derived in the present study. The difference in the transport system cost is about the same magnitude as the contingency used in this study.

Under subcontract to ORNL, Hydroscience, Inc., has evaluated media for intermediate temperature energy transport. ${ }^{3}$ Hot water, oil, and steam pipelines were compared on an economic basis. The pipeline costs published by Hydroscience were compared to the costs generated in the present study and, after accounting for escalation, the costs were found to be very consistent. 


\section{CONCLUSIONS}

Although highly dependent on the assumptions and costing methods, a conclusion of this study is that the transport of high temperature energy appears to be economically practical only for distances less than about $64 \mathrm{~km}$ ( 40 miles). Neither an HTS nor CHP transport system can be dismissed based on the preliminary economic evaluation conducted in this study. A steam pipeline is the least feasible system and is apparently a poor choice for any distance over $24 \mathrm{~km}$ ( $15 \mathrm{miles}$ ).

The cost of the pipe materials has been shown as the most significant factor in the HTS system cost. The use of plain steel would make the HTS system competitive with the CHP at long distances. Plain steel, however, is apparently suitable for HTS only when the temperature is held below about $450^{\circ} \mathrm{C}$ $\left(850^{\circ} \mathrm{F}\right)$.

The cost of HTS system is more sensitive to prime heat cost since its efficiency is lower than the CHP. The CHP, however, must have a very specific interface with a steam power plant in order to achieve this advantage.

The HTS system would benefit considerably from the use of a salt with a lower melting point than the sodium nitrate/nitrite mixture evaluated in this study. This would allow the flow rate of salt to be reduced and the size of the pipe accordingly. A survey of salts and liquid metals revealed few suitable candidates.

The EVA-ADAM CHP was identified as being the most developed and probably most practical of these systems. Practically no other system is under investigation which does not utilize media which are either highly toxic and/or highly corrosive. A possible exception is the $\mathrm{CO}_{2}$ methane reformer which may offer less complex chemical reactor systems.

\section{RECOMMENDATIONS FOR FUTURE WORK}

Due to the high cost of stainless steel, a lower temperature HTS system should be evaluated relative to the alternatives such as the $\bar{C} \bar{H} \bar{P}$ and perhaps an organıc tluıd. Wata from the KFA facllity should be incorporated in the study to identify the actual performance of the chemical reactors and condensers. The operation of the test loop in Germany provides an excellent opportunity to perform an economic evaluation with more realistic information on the performance of the entire CHP system.

Catalyst replacement costs should also be included in a more refined evaluation. Systems larger than examined in this study should be evaluated.

Basic research on heat transfer salts should be continued in order to provide data on materials compatibility. Development of a lower melting point salt with stability up $10550^{\circ} \mathrm{C}\left(1022^{\circ} \mathrm{F}\right)$ should bc pursued. 


\section{REFERENCES}

1. U.S. Department of Energy, Energy Information Administration, Monthly Energy Review, DOE/EIA-0035/ 5 (79), May 1979.

2. T. D. Anderson and E. C. Fox, Summary Report-Conversion to Coal in the Industrial Sector, ORNL/TM-6661 (January 1979).

3. Assessment of Long-Distance Thermal-Energy Transport: A Comparison Between Water, Steam, and Hot Oils, prepared by Hydroscience, Inc., OR NL/SUB-79/14274/1 (March 1979).

4. J. R. Tallackson, Electricity in Lieu of Natural Gas and Oil for Industrial Thermal Energy-A Preliminary Survey, ORNL/TM-5937 (February 1979).

5. J. R. Engel et al., Development Status and Potential Program for Development of Proliferation-Resistant Molten-Salt Reactors, ORNL/TM-6415 (March 1979).

6. "High Temperature Heating Media," Chemical Engineering Progress (May 1963).

7. J. L. Smee et al., Organic Coolant Summary Report, AECL-4922 (August 1975).

8. K. Kugeler, Thermochemical Cycles and Distribution of Process Heat, in Proceedings of the Solar High Temperature Industrial Processes Workshop, Sept. 28-30, 1978, SERI/0637-4.

9. Transmission of Energy by Open-Loop Chemical Energy Pipelines, Project 8990 Final Report, Institute of Gas Technology (June 1978).

10. T. G. Lenz, Proposal for Engineering Design Study of Conversion of Solar Energy to Chemical Energy Through Ammonia Dissociation, in proceedings of the Solar High Temperature Industrial Processes Workshop, Sept. 28-30, 1978, SER I/0637-4.

11. H. B. Vakil et al., Closed Loop Chemical Systems for Energy Storage and Transmission, COO-2676-1 (February 1978).

12. T. A. Chubb, Energy Collection and Transport Using the $\mathrm{SO}_{3} / \mathrm{SO}_{2}-\mathrm{O}_{2}$ Thermochemical Cycle; $\mathrm{PF}_{3} \mathrm{H}_{2}$ as a Possible Thermochemical Fluid, in Proceedings of the Solar High Temperature Industrial Processes Workshop Sept. 28-30, 1978, SERI/0637-4.

13. T. A. Chubb, Analysis of Gas Dissociation Solar Thermal Power System, Solar Energy, Vol. $17,1975$.

14. Chemical Safety Data Sheet SD-101 on Sulfur Trioxide, Manufacturing Chemists Association, 1976.

15. A. Weinstein et al., Sawing Solar Costs in Half, Solar Heating and Cooling, 1978.

16. M. W. Rosenthal et al., The Development Status of Molten-Salt Breeder Reactors, ORNL4812 (August 1972).

17. R. E. Thoma, ed., Phase Diagrams of Nuclear Reactor Materials, ORNL-2548 (November 1959).

18. T. T. Bramlette et al., Survey of High Temperature Thermal Energy Storage, SAND 75-8063 (March 1978).

19. H. F. McDuffie et al., Assessment of Molten Salts as Intermediate Coolants for LMFBR's, ORNL/TM-2696 (September 1969).

20. DuPont HITEC Heat Transfer Salt, E.I. duPont de Nemuurs and Co., Explosives Department, Chemical Products Sales Division, Wilmington, DE 19898.

21. Partherm Heat Transfer Salts, Technical Bulletin of Park Chemical Company, Detroit, Michigan, 1976.

22. M. D. Silverman and J. R. Engel, Survey of Technology for Storage of Thermal Energy in Heat Transfer Salt, OR NL/TM-5682 (January 1977). 
23. E. G. Bohlmann, Heat Transfer Salt for High Temperature Steam Generation, ORNL/TM3777 (December 1972).

24. R. Noyes, ed., Fuel Cells for Public Utility and Industrial Power, Noyes Data Corporation. Park Ridge, New Jersey, 1977.

25. M. H. Fontana, ORNL Breeder Reactor Safety Program LOA 2, 3, 4, and 5-Quarterly Technical Progress Report, April-June, 1979, ORNL/TM-7147 (February 1980).

26. J. H. DeVan, Cumpuilility uf Struitural Materials with Boiling Potassium, OR.NL/TM= 1361 (April 1966).

27. An Assessment of the Use of Chemical Reaction Systems in Electric Utility ApplicationsPhase II Final Report, SAND 78-8195 (June 1979).

28. J. L. Fried, Heat-Transfer Agents for High-Temperature Systems, Chemical Engineering (May 1973).

29. Proceedings of the Second Annual Thermal Energy Storage Contractors' Information Exchange Meeting, CONF-770955 (September 1977).

30. Telephone Conversation with Dick Allen, General Electric Company, Sunnyvale, California.

31. Heat Transmission and Storage, University of Houston Central Campus Energy Laboratory Newsletter, Vol. 1, No. 1, 1978.

32. J. T. Richardson and S. Das Gupta, Interfacing Methane-Carbon Monoxide Chemical Heat Pipes with Solar Towers: Preliminary Design and Economic Study, in Proceedings of the Solar High Temperature Industrial Processes Workshop, Sept. 28-30, 1978, SERI/0637-4.

33. Unpublished work by Rocket Research Corporation for EPRI, 1977.

34. T. N. Vezirogulu, ed., Hydrogen Energy, Plenum Press, New York, 1975.

35. J. W. Flock et al., Process Steam End Use for Solar Energy Using Chemical Heat Pipes, in Proceedings of the Solar High Temperature Industrial Processes Workshop, Sept. 28-30, 1978, SERI/0637-4.

36. Third Annual Proceedings of the Thermal Energy Storage Contractors' Information Exchange Meeting, CONF-781231 (December 1978).

37. J. J. Iannucci and J. D. Fish, Analysis of Solar Energy Conversion Processes: Systems Economic Impact of Thermochemical Storage Efficiencies, Presented at Atlanta ISES Conference, 1979.

38. W. E. Wentworth and E. Chen, Simple Thermal Decomposition Reactions for Storage of Solar Thermal Energy, Solar Energy, Vol. 18, 1976.

39. Chemical Reactions for Storage of High Temperature Solar Energy, University of Houston Central Campus Energy Laboratory Newsletter, Vol. I, No. 1, 1978.

40. K. M. Guthrie, Process Plant Estimating, Evaluation, and Control, Cräftsman Book Company of America, Solana Beach, California, 1974.

41. Union Carbide Corporation-Nuclear Division Standard Cusling Procedures, unpublishcd.

42. G. G. Leeth and C. F. Meyer, Gas Reactor International Cooperative Program Interim Report-HTR Multiplex Market Assessment, COO 4057-10 (September 1978).

43. J. E. Jones Jr. et al., Assessment of Very High-Temperature Reactors in Process Applications, Appendix 11-VHTR Process Heat Application Studies, ORNL/TM-5410 (Junc 1977).

44. R. N. Quade et al., Energy Distribution and Storage Alternatives with a Centralized Heat Source, in Proceedings of the 13th Intersociety Energy Conversion and Engineering Conference (August 1978). 



\section{THIS PAGE \\ WAS INTENTIONALLY \\ LEFT BLANK}


Table A.1. Basic cost for pipe materials

\begin{tabular}{rllr}
\hline $\begin{array}{c}\text { Pipe } \\
\text { diameter } \\
\text { [cm (in)] }\end{array}$ & $\begin{array}{c}\text { Wall } \\
\text { thickness }\end{array}$ & \multicolumn{1}{c}{ Material } & $\begin{array}{c}\text { Price } \\
\text { (\$/linear m) }\end{array}$ \\
\hline $61(24)$ & Sch. 10 & 304 SS, A 312 & 410 \\
$76(30)$ & Sch. 10 & 304 SS, A 312 & 509 \\
$102(40)$ & $10 \mathrm{~mm}$ & 304 SS, A 312 & 873 \\
$127(50)$ & $10 \mathrm{~mm}$ & 304 SS, A 312 & 1093 \\
$61(24)$ & Sch. 10 & Plain steel & 98 \\
$76(30)$ & Sch. 10 & Plain steel & 121 \\
$102(40)$ & $10 \mathrm{~mm}$ & Plain steel & 210 \\
$127(50)$ & $10 \mathrm{~mm}$ & Plain steel & 262 \\
$76(30)$ & $40 \mathrm{~mm}$ & A 106 B & 670 \\
$127(50)$ & $66 \mathrm{~mm}$ & A 106 B & 1818 \\
$178(70)$ & $51 \mathrm{~mm}$ & A 206 & 1936 \\
\hline
\end{tabular}

Table A.2. Other cost data used in estimates

Excavation (sandy loam soil), $\$ / \mathrm{m}^{3}$

Diatomacious earth insulation, $23 \mathrm{~cm}$ on $76-\mathrm{cm}$ pipe,

S/linear $\mathrm{m}$

Perlite insulation, $30 \mathrm{~cm}$ on $127-\mathrm{cm}$ pipe, $\$ /$ linear $\mathrm{m}$

Electric power supply line, typical $24 \mathrm{~km}$ of line plus $\mathbf{4 8} \mathrm{km}$ from source, $\$$

Hitec pump, including drive motor, $\$$

Gas compressor stations, including drive motor, $\$$ 
THIS PAGE

\section{WAS INTENTIONALLY \\ LEFT BLANK}




\section{APPENDIX B}


THIS PAGE

\section{WAS INTENTIONALLY LEFT BLANK}


Table B.1. Flow rates for transport systems

\begin{tabular}{lc}
\hline Medium & $\begin{array}{c}\text { Flow rate } \\
{[\mathrm{kg} / \mathrm{h}(\mathrm{lb} / \mathrm{h})]}\end{array}$ \\
\hline Hitec & $4.10 \times 10^{6}\left(9.03 \times 10^{6}\right)$ \\
Steam & $0.45 \times 10^{6}\left(1.00 \times 10^{6}\right)$ \\
EVA/ADAM & $3.10 \times 10^{5}\left(6.81 \times 10^{5}\right)^{a}$ \\
& $1.66 \times 10^{5}\left(3.65 \times 10^{5}\right)^{b}$ \\
\hline
\end{tabular}

${ }^{a}$ Reformer leg

${ }^{b}$ Methanator leg 
THIS PAGE

WAS INTENTIONALLY

LEFT BLANK 
ORNL/TM-7390

Dist. Cateogry UC-94

\section{Internal Distribution}

1. T. D. Anderson

2. S. Cantor

3. R. G. Chenoweth, Jr.

4. J. T. Cockburn

5. C. S. Daw

6. J. G. Delene

7. D. M. Eissenberg

8. J. R. Engel

9. E. C. Fox

10-14. R. L. Graves

15. F. P. Griffin

16. T. J. Hanratty

17. J. F. Harvey

18. H. W. Hoffman

19. K. O. Johnsson

20. J. E. Jones

21. W. K. Kahl

22. M. A. Karnitz

23. O. H. Klepper
24. R. E. MacPherson

25. M. Olszewski

26. S. A. Reed

27. J. L. Rich

28. M. W. Rosenthal

29. D. Scott

30. T. Shapiro (K-25)

31. M. D. Silverman

32. I. Spiewak

33. T. K. Stovall

34. J. F. Thomas

35. H. E. Trammel

36. D. B. Trauger

37. G. P. Zimmerman

38. ORNL Patent Office

39. Central Research Library

40. Document Reference Section

41-42. Laboratory Records Department

43. Laboratory Records (RC)

\section{External Distribution}

44. N. R. Baker, Institute of Gas Technology, IIT Center, 3424 S. State St., Chicago, IL 60616

45. Lyford Brown, Stone \& Webster Management Consultants, Inc., 90 Broad St., New York, NY 10004

46. T. A. Chubb, E. O. Hulbert Center for Space Research, Naval Research Laboratory, Washington, DC 20375

47. J. D. Fish, Sandia Laboratories 8452 , Livermore, CA 94550

48. I. Helms, Advanced Nuclear Systems and Projects Division, DOE, Washington, DC 20545

49. B. Mehta, Electric Power Research Institute, 3412 Hillview Ave., Palo Alto, CA 94304

50. A. T. Mr.Main, General Atomic Co., P.O. Dox 81608, San Diego, CA 92138

51. R. N. Quade, General Atomic Co., P.O. Box 81608, San Diego, CA 92138

52. V. Rabl, DOE Division of Energy Storage Systems, 600 East St., NW, MS 404, Washington, DC 20585

53. J. T. Richardson, University of Houston, Energy Laboratory, Central Campus, Houston, TX 77004

54. Neil. F. Richey, United Engineers and Constructors, 30 S. 17th St., Philadelphia, PA 19101

55. A. Rubin, Advanced Nuclear Systems and Projects Division, DOE, Washington, DC 20545

56-65. W. F. Savage, Advanced Nuclear Systems and Projects Division, DOE, Washington, DC 20.545

66. W. R. Smith, III, Babcock \& Wilcox, P.O. Box 1260, Lynchburg, VA 24505

67. Roberto Steiner, Stone \& Webster Engineering Co., 3 Executive Campus, P.O. Box 5200, Cherry Hill, NJ 08034

68. H. B. Vakil, General Electric Power Systems Laboratory, Corporate Research \& Development, Schenectady, NY 12301

69. Malcolm Williams, 285 Liberty Ave.. P.O. Bnx 2.951, Beaumont, TX 77704 
70. Charles Wyman, Solar Energy Research Institute, 1536 Cole Blvd., Golden, CO 80401

71. Office of Assistant Manager for Energy Research and Development, DOE, ORO, Oak Ridge, TN 37830

72-178. Given distribution as shown in DOE/TIC-4500 under category UC-94 